\title{
Recent advances in drying at interfaces of biomaterials
}

Thijs Defraeye $^{a, b} *$, Andrea Radu $^{b}$, Dominique Derome ${ }^{a}$

${ }^{a}$ Laboratory for Multiscale Studies in Building Physics, Swiss Federal Laboratories for Materials Testing and Research (Empa), Überlandstrasse 129, 8600 Dübendorf, Switzerland

${ }^{b}$ Chair of Building Physics, Swiss Federal Institute of Technology Zurich (ETHZ), Stefano-Franscini-Platz 5, 8093 Zürich, Switzerland

\section{* Corresponding author}

- E-mail defraeye@arch.ethz.ch

- Tel. $\quad+41(0) 587654790$

- Fax. $\quad+41446331041$

Journal: Drying Technology

Running head title: Interfacial drying of biomaterials

This document is the accepted manuscript version of the following article:

Defraeye, T., Radu, A., \& Derome, D. (2016). Recent advances in drying at interfaces of biomaterials. Drying Technology, 34(16), 1904-1925. http://doi.org/10.1080/07373937.2016.1144062 


\section{Abstract}

A better insight in heat and mass transport across interfaces of biomaterials with their environment, particularly at the microscale, is a key element in improving dehydration processes. Recent advances in interfacial drying are targeted, including evaporation from microscopic pores, droplets or micro-perforated membranes, and drying of soft cellular tissue, such as fruit. Manufacturing of thin biopolymer layers, such as (edible) films and coatings, is discussed as well as their performance as barriers at product-environment interfaces. The physical processes at play are illustrated, recent insights are highlighted and a future outlook is given. These interfacial processes are critical for controlling the processing conditions during drying and for tailoring the structure and quality of biomaterials.

Keywords: food, hydrogel, interface, drying, tailored properties 


\section{Introduction}

Dehydration implies the removal of water from natural and manufactured materials including food, textile, wood, ceramics and pharmaceuticals [1]. Various established and novel methods are used to drive the drying process, such as hot-air convection, freeze drying, superheated steam drying, microwave-assisted drying or hybrid drying techniques [2, $3,4,5,6,7]$. Many of these techniques supply heat for evaporating water. This heat is transferred to the product via the interface with its environment by convection, radiation or conduction. Heat can also be supplied directly into the material matrix, for example with microwaves (Figure 1). Moisture, however, has to be removed via the interface, regardless of the dehydration method being used. Often, the heat and moisture transport processes in the vicinity of this interface play a key role in the drying kinetics $[8,9]$, in addition to the bulk transport inside the porous product and the surrounding environment.

Several complex phenomena occur at product-environment interfaces during drying $[10,11]$, of which some are illustrated in the paragraphs below. Large temperature and moisture gradients are found in the air boundary layer [12] (Figure 1). Also, the occurrence of micro-roughness can highly enhance or restrict the convective transfer rates $[13,14]$. In the absence of a liquid film on the exterior surface of a porous material, only a part of this interface area contains liquid water (Figure 2a), namely the water-filled pores [15]. Thereby, these exposed surfaces cannot be considered fully wetted, even during the constant drying rate period, when the drying front is located at the surface (Figure $2 \mathrm{~b}$ ). Later on, the drying front recedes into the material, indicating the start of the decreasing drying rate period. At this point, the complex interplay between boundary-layer transfer and moisture/heat diffusion inside the material determines the drying rate. The large moisture gradients that appear inside the material near the interface (Figure 1) induce also an altered moisture permeability, as the latter is often highly dependent on moisture content [16].

The partial surface coverage by moisture sources is found to influence the drying kinetics significantly [17, 18]. This phenomenon is of high relevance as practically all porous materials experience such a reduced wetted surface. A similar situation is found for perforated membranes (Figure 2a), which are used as moisture barriers between wet materials and their environment. Typical examples are membranes for evaporation suppression of free water surfaces [19], microcracks or lenticels in the fruit cuticle [20] or stomatal openings in plant leaves [13], which regulate leaf transpiration. Such partial coverage is also encountered with impermeable surfaces of biomaterials, covered with small droplets 
(Figure 2a). Typical examples are droplets of rain or pesticide spray on fruits or plant leaves. Their evaporation kinetics, thus the droplet lifetime, determine the pesticide efficacy and the risk of contamination by pathogens [21, 22]. As such, there is a wide range of applications where accurate predictions of moisture transfer of partially wetted or partially exposed surfaces is needed.

On another note, drying is a key processing and preservation technology for cellular fruit tissues, processed food and food gels (Figure 3), which are soft materials. Often, the primary aim is to increase shelf life by reducing the water activity below an acceptable level. Other targets are ensuring prime product quality, such as rehydration capacity and sensory properties (e.g. structure, texture, mouthfeel), while at the same time maintaining a high throughput and minimal operational costs. For these soft materials, shrinkage near the interface can lead to a thin dry layer of material, which acts as a clear barrier against dehydration $[23,24,25]$. The mechanical properties near the interface are also altered due to their dependency on the moisture content, which can lead to case hardening or cracking damage [26]. These interface phenomena thus play a key role in the drying process.

Furthermore, permeable biopolymer layers are applied as manufactured interfaces between the product and its surroundings. These bio-barriers are often (hydro)gel-based [27] and serve as functional food components [28, 29, 30], stimuli-responsive membranes [31], scaffolds in tissue engineering, drug delivery vehicles or optical biosensors [32, 33, 34, 35]. Edible coatings, for example, control the transport of moisture, metabolic gasses and volatile compounds from intact and fresh-cut fruit and vegetables, as well as from processed food [30, 36]. Edible coatings enhance quality and shelf life, but can also facilitate further processing, and edible films serve as biodegradable packaging materials [37]. These biopolymer layers can be manufactured separately on a substrate (Figure 4a) and then applied onto the product of interest, or can be directly applied onto the product (Figure 4b). Apart from their composition and film forming characteristics, the drying conditions highly affect the structure of the biopolymer layer, which in turn determines the barrier performance $[38,39,40]$. The transport processes within and through these thin interface layers and their microstructure are key determinants to take into account for their design, manufacturing and successful use of the end product.

Despite their significant impact on drying kinetics, most of the aforementioned interface phenomena have received little attention, far less than bulk product dehydration, equipment design and performance, or process control and 
optimisation. A better understanding and quantification of these interfacial exchange processes of biomaterials with their environment during drying can help to improve drying processes, for example by optimising process conditions. Such insight can also aid in controlling the final (micro)structure of the dried biomaterial in order to achieve desired functional properties, such as moisture barrier performance of edible films.

This review targets recent specific advances in a selection of drying phenomena occurring at biomaterial-environment interfaces, namely the three topics depicted in Figures 2 to 4, which are of particular relevance to drying technologists: (1) evaporation from microscopic pores, droplets or micro-perforated membranes; (2) drying of soft cellular tissue and gels; (3) manufacturing of thin biopolymer layers, such as (edible) films and coatings, and their performance as barriers at product-environment interfaces. Particularly edible biological materials are targeted - thus food - including fresh fruit and vegetables, processed foods and edible films and coatings. This class of materials has promising industrial applications towards more sustainable process engineering [10]. We illustrate the physical processes at play and discuss state-of-the-art numerical and experimental methods, as these are two, often complementary, ways to get more insight. Afterwards, the latest insights and the possible impacts in each field are highlighted. Finally, future challenges in interfacial drying are discussed and we hint to solutions to accommodate for them. 


\section{Advances in interface exchange processes}

\section{$\underline{2.1 \text { Discrete microscopic moisture sources }}$}

Unless porous materials are covered with a water film, they only have a part of their external surface via which water vapour exchange can occur, namely via the exposed pores at the surface. The same holds for impermeable surfaces, which are only partially covered with small droplets, or for perforated moisture barriers between a wet material and its environment (Figure 5a, Figure 2a).

Partial surface coverage with such so-called discretely-distributed moisture sources alters the convective moisture transport in the boundary layer, compared to a fully wet surface, and will affect the drying rate. This phenomenon is investigated for microscale droplets on impermeable surfaces $[18,41,42,43,44]$, capillary porous materials $[15,17,45$, $46,47,48,49,50]$, perforated barriers on free water surfaces $[19,51]$, lenticels in the fruit cuticle [52] and leaf stomata $[41,53]$. A typical example is illustrated in Figure $5 b$, where evaporation from discrete stomata from a leaf via the boundary layer is shown.

\subsubsection{Modelling and experiments}

Analytical studies are performed on quite simple air flow configurations $[42,53]$. Experimental research often considers rather large moisture sources (> $1 \mathrm{~mm}$ ) and evaluates only the total convective transfer rate from the surface $[17,43$, 44, 53]. The most recent advances are made on the numerical side (e.g. [17, 18, 41, 46, 47, 49]). Some of these studies use computational fluid dynamics (CFD) to solve the air-side transport. With this approach, the local convective exchange processes in the boundary layer can be determined, which affect the vapour concentration profiles in the vicinity of the microscopic moisture sources. Often vapour transport is modelled as a passive scalar, which implies that it does not affect the airflow field. As vapour transport is not directly coupled to the airflow calculation, the computational complexity is reduced. Attaining such high resolution at these small scales is very challenging experimentally. Some techniques have been evaluated recently $[54,55]$, but only look at single droplets.

\subsubsection{Advances}

The aforementioned research shows that the vapour flow rate for surfaces that are only partially covered with moisture sources $\left(G_{c, w}\right)$ is indeed lower than for a fully wetted surface. There is a strong nonlinear dependency on the coverage 
ratio $\left(A_{\text {eff }} / A\right)$, the size of the sources $(d)$ and the air speed $(U)$, thus the boundary layer thickness $\left(\delta_{V S L}=\right.$ thickness of the viscous sublayer, Figure $5 c$ ). A relatively high vapour flow rate is obtained when the surface coverage is high, the source size is small and the boundary layer thickness large (i.e. low speeds). In this case the surface behaves very similarly as a fully wetted surface. This behaviour is found to be valid for both microscopic as well as macroscopic sources [51]. As a result, porous materials with an inherent partial surface exposure, namely only the pores at the surface, can still have a quite high drying rate, particularly during the constant drying rate period (CDRP). Obviously, this CDRP drying rate is found to be material dependent [50], as the size and the amount of pores at the surface differs.

\subsubsection{Impact}

These findings are relevant for quantifying the convective mass transfer coefficients (CMTCS) that are used to predict the vapour flow rate from products or water surfaces in dehydration modelling. CMTCs can be determined from mass transfer experiments, CFD simulations or the heat and mass transfer analogy. Often uniform boundary conditions are imposed, namely a fully-wet surface or a constant-temperature surface $[8,13]$. For the latter, only heat transfer is considered, so without moisture transport, where the CMTC is estimated using the heat and mass transfer analogy. The use of CMTCs resulting from such uniform conditions will thereby lead to an overestimation of the convective transfer rates for surfaces with only partial exposure, compared to a uniformly-wetted surface. This overestimation is most pronounced for large source sizes, high air speeds and low surface coverage (Figure 5c). In addition, the discrepancies can change during the drying process, namely if the surface coverage $\left(A / A_{\text {eff }}\right)$ decreases as pores dry out (from point 1 to 2 in Figure 5c). For droplets that are not pinned, the situation is even more complex. In addition to the decreasing coverage ratio, the droplet size $(d)$ also decreases, as they gradually dry out (from point 1 to 3 in Figure $5 c$ ). A similar phenomenon occurs when gels dry as shrinkage makes that the pore size decreases (Figure 3b). Gels however often behave close to fully wet surfaces due to their very small pore size $\left(\sim 10^{1} \mathrm{~nm}[56]\right)$. A detailed understanding of this partial-surface-coverage effect is also critical for designing permeable membranes or porous biopolymer layers with specific moisture transport properties, which are tailored to actively control, reduce or enhance evaporation.

\subsubsection{Future work}

Despite the recent experimental progress, new insights are particularly expected to come from the modelling side, where several model advances are in reach. So far, the simulated airflow fields are often very simple, such as laminar 
fully-developed flat-plate flow, and only a few studies targeted turbulent flow $[18,41,48]$. Furthermore, the nonisothermal nature of the evaporation process [49] and the interaction with the transport inside the porous material [17] have scarcely been considered. The latter becomes particularly important at high heating rates, for example with microwave heating, since then vapour is transported convectively out of the pores, driven by high gas pressures [11]. Finally, the complex dependency of the vapour flow rate on the microscopic surface sources (in terms of size, air speed, surface coverage, Figure 5c) could be incorporated in models at the macroscale level. This has only been pursued by [57], to the best knowledge of the authors. 


\subsection{Dehydration of soft cellular materials}

Soft cellular tissues such as fruit and vegetables typically are composed out of cells (e.g. $~ 100 \mu \mathrm{m}$ for apple), which are predominantly composed of water, and intercellular air-filled spaces ( 10-20\% in volume, Figure 6$)$. The cell membrane ( $10 \mathrm{~nm}$, a phospholipid bilayer with embedded proteins) contains the water-based cytoplasm and organelles, which act as a viscoelastic filling of the cell. The membrane is pressed against the elastic cell walls (thickness $\sim 1 \mu \mathrm{m}$ ) by turgor pressure. Water transport in cellular tissue occurs via three pathways: apoplastic, symplastic and transcellular (Figure 6). Symplastic water transport occurs through the cells via plasmodesmata (diameter $\sim 50 \mathrm{~nm}$ ), which connect cells, and is considered as the most relevant transport pathway. Apoplastic water transport takes place via the cell walls and intercellular spaces, so bypassing the cells. Transcellular transport occurs directly from one cell to another, through the cell walls and membranes. A representation of the cellular structure is shown in Figure 7, namely for fresh fruit tissue (Figure 7b) and for dried tissue (Figure 7a).

Dehydration of such soft cellular structures involves significant changes in volume (shrinkage) and pore structure. Different stages can be discerned, which are illustrated in Figure 8. When cells are still turgid, so under turgor pressure, they shrink. Mostly symplastic water is lost, since the apoplastic water content only decreases at the last stages of drying $[58,59]$. As such, the change in water content of the tissue is almost linearly dependent on its overall decrease in volume, which is called free shrinkage [60]. In a later stage of drying, the cellular matrix provides sufficient mechanical resistance to render the macroscopic volume reduction smaller than the amount of water removed, leading to a nonlinear relationship between volumetric shrinkage and water content.

When the turgor pressure in a cell drops to zero at low water contents, the cell protoplasm detaches from the cell wall, a process called plasmolysis [61]. The cell membrane can also break, which is called lysis. As the cell membrane provides the largest resistance to water loss, the breakage of the cell membrane will speed up drying significantly since then symplastic liquid water fills the intercellular spaces and is also absorbed into cell walls [62]. In addition to shrinkage, plasmolysis or lysis of individual cells, cells walls have been observed to break, collapse or detach from adjacent cells $[59,63,64]$. Furthermore, the mechanical properties of the tissue can change from the rubbery to the glassy state, inducing case hardening $[65,66]$. The sensory properties and palatability are also affected by the textural changes at the interface [67]. 


\subsubsection{Modelling and experiments}

The bulk of the research on cellular tissue dehydration at the microscale relies on experiments. The focus is mainly on determining changes in microstructure and moisture permeability, but also in color and rehydration capacity. Microscopic techniques are prevalent here, including scanning electron microscopy (SEM) [68, 69, 70, 71, 72]. More advanced 3D imaging is used as well to investigate the microstructure of fresh and dehydrated cellular foods at steady state conditions, including X-ray computed tomography $[73,74,75]$ (Figure 7b).

As an alternative for studying dehydration of soft cellular materials at microscale level, two numerical approaches are recently developed. In a first approach (Figure 9a, [58]), a 2D finite-element model (FEM) for microscale water and gas transport [76] is coupled to a cell micromechanics model [77] to capture dehydration-driven mechanical deformation of the cellular matrix. Such deformation is illustrated in Figure 9a. A second approach involves a mesh-free particle-based model (Figure 9b, $[78,79]$ ), based on previous particle-based models [80]. The cell protoplasm is modelled using smoothed particle hydrodynamics (SPH) and the cell wall is modelled using the discrete element method (DEM). This particle-based model has the advantage that large deformations can be captured, including cell warping and wrinkling, as illustrated in Figure 9b. However, in contrast to the first approach [58], the 2D cellular structure is idealised with almost no intercellular air spaces, thus low porosity, and cell membranes are not accounted for explicitly.

\subsubsection{Advances}

The microstructural changes that are induced during dehydration of a soft cellular material start at the cells near the airproduct interface. These structure transformations are found to exhibit a large dependency on the process temperature and drying method $[81,82]$. Such microstructural changes highly affect the effective (macroscopic) moisture transport properties. As an example, the moisture transport pathways can be altered from intracellular to extracellular pathways if cell membranes break [62]. In this context, the dehydration of a soft cellular material has been observed to lead to the development of a thin layer of dried-out cellular tissue at the interface for forced convective drying [23]. This collapsed cellular matrix seems to act as a natural moisture barrier due to its lower permeability, protecting the fruit from further dehydration. Such a diffusion barrier could also explain why many fruit and vegetable tissues have a very short CDRP $[83,84,85]$. The resistance to moisture transport of the partially dried cellular material, in addition to the boundarylayer resistance, significantly prolongs the total drying time. At low convective drying rates however, the product 
surface can remain moist for a longer time, i.e. the product is in the CDRP, since such a dry tissue layer does not develop. In this case, the transfer of moisture inside the material to the surface is faster that the convective removal through the boundary layer. Next to the strong dependency of the drying behaviour on the drying conditions, also the speed and level of tissue dehydration as well as rehydration history are important. Hysteresis effects have been observed, which are attributed to changes in the amount of sorption sites caused by microstructural deformations but also by changes in crystallinity of sugars $[86,87,88]$. Transport in cellular food tissue is also of interest in the context of enriching foods with functional agents, for example by vacuum impregnation [89, 90].

\subsubsection{Impact}

A detailed understanding of the transformations occurring within this cellular structure, especially at the interface, is critical to tune drying conditions in a more goal-oriented way. Such insight should also allow to better control the final product microstructure in order to achieve enhanced functional properties, such as rehydration behaviour, sensorial profile or palatability [39]. Such insight could also aid in optimising pre-treatments, like osmotic drying [87, 91], or hybrid techniques such as convective-ultrasound drying $[92,93,94,95,96,97,98]$, given that these techniques rely on disturbing or destroying the cellular structure at the interface or inside the bulk tissue to intensify moisture removal [2].

\subsubsection{Future work}

Next steps in experimental imaging work should use the high spatial and temporal resolution available at synchrotron facilities to probe into the three-dimensional changes in the cellular structure and water transport during dehydration. Compared to steady-state imaging of the fresh and dry states, such dynamic tests could monitor cell wall collapse and membrane breakage within the tissue.

Novel modelling approaches $[58,78,79]$, based on SPH-DEM or micro-FEM, successfully capture cell dehydration and deformation in a dynamic way, but should be improved. They now assume that cells are turgid, so at relatively high moisture content, by which detachment (plasmolysis) and breaking of the cell membrane (lysis) cannot be captured. In addition, they assume isothermal conditions, by which they do not capture the lower product temperature, compared to the air temperature, often observed during drying, caused by the latent heat of evaporation [99]. 
Another interesting idea that can be explored further is the use of surfactants to enhance drying rates and quality of biomaterials [64]. Surfactants reduce the surface tension between the liquid and gas phase (vapour), so the interfacial energy. Surface water molecules are brought to a lower energy state by which the surfactant actually stabilises the molecules. For free water surfaces, surfactants are often used to suppress evaporation [100]. For porous materials, surfactants reduce the maximal attainable capillary stresses inside the pores (see Figure $2 \mathrm{~b}$ ) and thereby also the product shrinkage during drying. Surfactants can also influence the contact angle [101]. They have been successfully used to reduce cracking for ceramic materials when added to water during preparation [102]. With cellular biomaterials, surfactants had an additional effect as they induced cell tissue damage after vacuum infiltration [103]. The most likely reason is that the surfactants dissolve the lipid-based cell membranes, leading to faster drying. The effects of surfactants on dehydration, by external application onto the product surface or by impregnation into the matrix, could be a way to obtain more porous structures and faster drying. 


\subsection{Biopolymer layers}

Permeable biopolymer layers include coatings and films. Films have a thickness in the micron range $(<250 \mu \mathrm{m}[104])$ whereas coatings are much thinner, typically between a few $100 \mathrm{~nm}$ thick up to a few microns [105]. We particularly focus here on hydrogel-based biopolymer films and coatings, which are often used for food applications.

Hydrogels are made by gelation of a hydrocolloid, namely dispersed particles (biopolymers) suspended in water. As a result, a hydrophilic biopolymer network with a chemical or physical cross-linked structure is obtained. This network can contain large amounts of water but it does not (easily) disintegrate in water (Figure 10). A well-known example of hydrogel-based layers are edible films and coatings [28, 29, 30, 106, 107, 108]. These layers are often based on biopolymers such as polysaccharides (e.g. agar, alginate, cellulose derivate, chitosan, pectin, gums, starch) or proteins (e.g. gelatine, whey, soy, gluten, zein). Composites with hydrophobic biopolymers (e.g. lipids) also exist. In general, polysaccharides are applied to control transmission of oxygen and other gasses, proteins enhance mechanical stability and lipids reduce water transport through the layer [109]. Next to applying a biopolymer coating explicitly on the product surface, one could also use the biopolymers that are already available at the material surface as ingredients to form the biobarrier. For fresh-cut fruits, for example, only calcium salts are applied onto the fruit. The salt ions interact with the pectin polymers at the wounded surface to form a cross-linked network, thereby reducing softening of the tissue [110].

Thin, permeable biopolymer layers are used as functional interfaces between products and their environment, to limit or control transport between them. Edible coatings, for example, are applied onto fresh fruit and vegetables, dried fruit, bakery products, French fries, meat and chocolate products [36, 109]. Films are used as biodegradable packaging materials. These thin layers help to control the release of moisture, metabolic gasses or volatile compounds (aromas) from natural and processed foods, in order to preserve the sensory and nutritional quality of the product and to extend its shelf life $[89,111]$. As such, biopolymer layers can be used to enhance natural barriers, such as the fruit cuticle, or act as substitutes of these barriers. A typical application is fresh-cut or peeled fruit, where the natural barrier is removed $[105,106]$. Biopolymer layers are also applied to reduce solute uptake into fruits during osmotic dehydration $[29,112]$. In composite foods, coatings are used to form barriers between components, for example to prevent pizza dough from losing its crispiness due to moisture migration from the tomato paste [113]. 
Next to protecting the product from its surroundings or regulating transport between them, biopolymer layers are also convenient media for embedding/carrying functional compounds. These compounds help in retaining product quality by controlled release of these compounds (antimicrobials, antioxidants) or by enhancing nutritional or sensorial properties for the consumer (nutraceuticals, probiotics, flavour or colour, texture enhancers) [89, 110, 114, 115, 116, 117]. From the above, it is clear that biopolymer layers are ubiquitous in the food industry and of high practical relevance.

The focus of this study is mainly on edible biopolymer layers due to the rapidly growing interest in these materials. Reasons of such interest are that: (1) biopolymer layers can be consumed with the food or rapidly degrade compared to plastics, hence reducing packaging waste and forming an alternative to synthetic polymer-based packaging; (2) they reuse industrial biomass by-products, hence reducing biomass waste; (3) they form a perfect medium to enhance the quality and shelf life of fresh and processed food, as antimicrobials, antioxidants and texture enhancers are applied directly where they are needed, i.e. at the surface; (4) such layers can serve as biocompatible vehicles to carry functional compounds for customers, to protect the compounds from degradation and to control compound release; (5) there is a large potential for further improvement as industrial implementation is still on the rise.

Two interesting aspects of biopolymer layers will be targeted below. First, dehydration during manufacturing of the film or coating is looked at. Apart from the layer composition and film forming characteristics, the dehydration step plays a key role in the resulting (micro)structure and barrier properties. Second, the efficacy of biopolymer layers as functional interfaces to influence transport between the product and its environment is discussed. 


\subsubsection{Manufacturing of biopolymer layers}

Films are produced "stand-alone", i.e. by a separate process, mostly by solvent casting but also by extrusion. Coatings are directly applied onto the product by dipping or spraying [118]. Most of these processes use a colloidal solution (sol) of biopolymers in a liquid solvent, for example water in hydrogels. This solution is turned into a gel by cross-linking the biopolymers into a solid polymer network (gelation, Figure 10) and by removing the solvent through drying (Figure 4). Convective air-drying is often used [105], which induces significant shrinkage of the porous microstructure due to surface tension effects in the small pores (Figure 3), leading to so-called xerogels. Other methods that better preserve the gel microstructure are supercritical drying or freeze drying (lyophilisation, [119]), leading to so-called aerogels. Next to gel composition and the cross-linking process, the drying method, conditions (e.g. temperature, humidity, $\mathrm{pH}$ ) and resulting kinetics are key determinants of the resulting properties of the dried biopolymer layer $[38,40,120,121]$.

The basic physics of gel drying are known for a long time and have been clearly documented $[101,56]$. The different stages of drying of a deformable gel are illustrated in Figure 3b. The constant drying rate period (CDRP) is usually very pronounced with hydrophilic gels, and the decreasing drying rate period (DDRP) can actually be quite short [38, 120]. During the CDRP, the volume shrinkage equals the amount of water lost and capillary forces are very limited, but the porous gel matrix gets denser. Once this matrix is rigid enough to withstand further contraction, the DDRP sets in [119], which is composed of two periods (Figure 3b). The small pores in gels ( $10^{1} \mathrm{~nm}$ [56]) make that capillary forces can become very large (see Figure 2b). As such, these forces can even induce mechanical damage such as cracking, especially at the end of the CDRP. As a gel typically shrinks with a factor 5 to 10 by volume, the pore size decreases significantly by which the capillary forces increase during drying [56]. At the end of the drying process, when capillary forces disappear, a volume increase can occur, the so-called springback effect [122]. With thick films or just bulk gels, a thin dry layer can form at the interface [24]. This dry skin or shell acts as a diffusion barrier, slowing down dehydration. During drying, the biopolymer layer can also become brittle since the glass transition temperature is a function of moisture content.

Different additives are applied to improve the manufacturing of films and enhance their final quality. Surfactants are used to promote spreading of the substrate by the film, but also act as antifoaming agent [40]. Surfactants can also alter the capillary stresses inside the film, since such stresses are dependent on the magnitude of the surface tension and the 
contact angle. Plasticisers are applied to enhance the flexibility of the film, by making the film less brittle, and also reduce the amount of micro cracks in the film $[40,109,123]$. Fibres can be added, for example to enhance mechanical strength and dimensional stability.

\subsubsection{Modelling and experiments}

Gels are often used as model systems of soft deformable materials. Thereby a vast amount of experiments and modelling work is done on their dehydration process, which is not covered here in detail. Typically, for modelling gel drying, moisture and energy balance equations are combined with empirical shrinkage models or with models solving explicitly the mechanical balance equations. Modelling efforts on (thin) gel drying can be found in $[24,122,124,125$, 126], including reaction engineering approaches to capture the drying kinetics. On the experimental side, techniques for determining the final structure and properties of biopolymer layers after drying (discussed below) are also used for monitoring the changes during drying, for example by sampling at different times [127]. For dynamic, online monitoring of the dehydration process, gravimetric measurements are commonplace $[38,120]$. In addition, nuclear magnetic resonance $[128,129]$ and X-ray imaging $[124]$ have been applied to visualise the moisture profiles within gels. Also small angle X-ray scattering has been used to study the dynamics of film drying [130]. Recently, ATR-FTIR spectroscopy is used to gain more insight into the film forming mechanism during drying of solutions of pullulan and alginate [131]. Inverse microscope Raman spectroscopy has been applied to measure water content in films [132].

\subsubsection{Advances}

Using these numerical but, especially, experimental tools, many research groups are currently engineering gel-based, biocompatible and/or biodegradable layers with unique properties, such as altered moisture diffusivity. Their main focus is on synthesising the porous microstructure $[34,126,133]$ with a specific porosity, pore size distribution, pore interconnectivity and tortuosity. Recent efforts are going into fabricating multi-porosity layers with microscale to nanoscale porosity, so-called hierarchical porous materials $[134,135]$. An example is shown in Figure 11 , where a hierarchical porous structure is depicted. Drying is shown to play a main role in the production of some of these hierarchical structures $[136,137,138]$. Drying affects, for instance, the assembly process of dispersed droplets or bubbles. On another note, structuring of self-healing hydrogel layers is also explored recently [139]. 
Other interesting developments include composite and multilayer films, which serve, for example, as alternatives for conventional edible coatings $[28,105,140,141]$. Composite blends aim at combining the best characteristics of the ingredients, such as the use of lipids to reduce the water permeability of hydrophilic polysaccharide films [29]. Multilayer films are ideal to incorporate functional agents. A promising technique to produce very thin multilayer coatings, so called nanolaminates [117], is layer-by-layer electrodeposition using polyelectrolytes [28, 29, 110, 117, 142], as illustrated in Figure 12. Here electrostatic interactions make that the different ingredients adhere to one another and form a thin coating. The design of more robust nanolaminates is of key interest, as their small thickness often makes them quite fragile.

A very recent development related to dehydration of biopolymer hydrogels is the fabrication of polysaccharide aerogels $[137,143]$. In contrast to xerogels, which shrink significantly, aerogels are dried in such a way that they maintain about the same porosity as the initial wet gel. This minimal shrinkage leads to a light, highly porous product with a large surface area $[144,145]$. These structural aspects lead to good thermal insulation and a high adsorption capacity. The use of biomaterials for producing aerogels, such as polysaccharides, is a highly active area of research. The main reasons are that such aerogels (re)use biomass, such as seaweed [146], and that they are food-grade materials. These polysaccharide aerogels can be applied for ecological packaging [143] or for catalysts and catalyst supports [145]. Despite their potential, the commercial application of polysaccharide aerogels is only incipient [137].

\subsubsection{Impact}

A better understanding of the impact of drying process conditions and drying kinetics on the porous microstructure of biopolymer layers and their resulting properties is critical to enhance their performance. As such, particular properties can be tailored to a specific application, for example for moisture transport, nutritional/sensorial quality or mechanical stability. Such insight also helps in exploring more energy-smart drying methods. A typical example is the use of methods that require less liquid to be evaporated, so less latent heat, for instance by using an extrusion process or plasticisers [105]. On a more fundamental level, one could also look at designing polymer networks that bind the bound water more loosely. In contrast to the free (liquid) water, this bound water is removed at the later stages of drying, where a lower binding energy could lead to a lower heat of desorption for the bound water. 


\subsubsection{Future work}

Several advances are required to further accelerate R\&D in biopolymer layer manufacturing and structuring. Drying processes of biopolymer layers should be monitored in a more dynamic way and in 3D, for example with nondestructive imaging. With these techniques, one can probe in real time the moisture migration within the material and the microstructure development during drying. In addition, future experiments should combine multiple experimental techniques, as well as techniques at different scales. On the modelling side, it would be of interest to perform molecular dynamics simulations [147] to better understand the interactions between the various components of hydrogels and their effect on shrinkage during drying. To fully analyse all impacts of the drying process on a biopolymer layer, further steps should be taken towards a multi-parameter multiscale evaluation, combining experiments and modelling.

Linking the process parameters to film/coating microstructure and functionality is essential for the development of advanced biopolymer-based barriers. Optimisation of the drying process should become more systematic, by following an iterative procedure [148]: first the recipe for the biopolymer layer is formulated, then the layer is dried and afterwards the relevant quality characteristics are determined. Multiple feedback steps are then used to change the initial product formulation or process conditions until a satisfactory quality is obtained. 


\subsubsection{Biopolymer layers as interfaces}

The use of biopolymer layers as functional interfaces between products and the environment, for example to limit or control moisture transport, is discussed here. Their efficacy is determined by their thickness, barrier properties (gas, moisture, aromas), mechanical properties and optical properties, but also by their water sorption behaviour and biocompatibility. These properties are strongly determined by the obtained microstructure. The efficacy of these thin interface layers is also dependent on their interaction with both product and environment, as illustrated below.

Hydrophilic biopolymer-based layers, such as many edible films, show a clear water sorption behaviour, which can include hysteresis (Figure 13). The hydrophilic nature is induced by the biopolymers but also by other components, such as plasticisers $[149,150]$. Thereby, dry biopolymer layers often easily rehydrate upon contact with water (vapour) from the surrounding air or from the product on which they are applied. At first, the hydrophilic groups absorb water but at higher relative humidities, the swelling exposes the hydrophobic groups as well, by which they can also exert forces on the water molecules $[105,151]$. Apart from this bound water, free water will invade the pore space later on. Water adsorption in hydrogels is accompanied by swelling. Swelling stops when the expansive forces are equilibrated by the resistance of the cross-linked network.

Their hydrophilic nature makes some films not very effective as water (vapour) barriers, by which they are not successful in limiting moisture loss from fresh-cut fruit for example. Their moisture permeability $\left(K_{m}\right.$, also called water vapour permeability WVP) is typically determined using standard methods $[152,153]$. In such measurements, often a rather large relative humidity differential $(\Delta R H)$ is imposed over the sample, e.g. $0 \%-90 \%$, as can be seen from Figure 14a for different experiments. The permeability is shown to vary as a function of $\Delta R H$ (thus the gradient) in Figure 14b, where a $\mathrm{RH}$ of $0 \%$ is imposed at one side of the film for all cases.

Larger $\mathrm{RH}$ differentials imposed over the film $(\Delta R H)$ imply a larger average water activity inside the material $\left(\mathrm{a}_{\mathrm{w}} \sim \mathrm{RH}\right)$ when starting from $\mathrm{RH}=0 \%$, thus also higher capillary pressures $p_{c}$ (Figure $14 c,[153,154,155]$ ). Here, $p_{c}$ is similar to the water potential and equals $\rho_{l} R_{v} T \cdot \ln \left(a_{w}\right)$, with $\rho_{\text {I }}$ the liquid water density, $R_{v}$ the specific gas constant of water vapour and $T$ the temperature. The permeability typically increases with the water activity inside the barrier (Figure 14b). As such, the performance of the barrier becomes highly dependent on the humidity conditions of the product and its 
environment [156], so the resulting humidity differential over the barrier. Furthermore, it is found that the physical state of the water in contact with the film - liquid or vapour - also can affect the mass transfer rate through a film [113].

This moisture-dependent barrier efficacy is illustrated with an example in Figure 15. Here, an identical moisture barrier is evaluated as applied on fresh-cut fruit (left) and on the peel of intact fruit (right). Due to the larger overall water activity inside the barrier when applied onto fresh-cut fruit, its permeability will be higher than it would be when applied on the peel of an intact fruit. This moisture dependency of the barrier permeability can also affect the product dehydration process: a fully rehydrated barrier can quickly shut off water loss when switching from first to second drying phase, as water activity decreases. Although this leads to slower dehydration, it can positively influence product quality by inducing more homogeneous dehydration [37, 157].

Currently, the dependency of the permeability on the water activity is rarely taken into account and the permeability is often only measured at a single $\mathrm{RH}$ differential $(\Delta R H)$. One of the reasons is that permeabilities are mostly determined in the context of comparing barrier compositions for a certain application, so where the different films are exposed to similar environmental conditions $(\Delta R H)$. When desired, the vapour permeability could be reduced by treatments inducing chemical cross-linking [140] or by the use of surfactants [150].

Another performance characteristic of biopolymer layers is their gas barrier function. Edible films, for example, help controlling the internal atmosphere of fresh and minimally-processed (fresh-cut) fruit, by which such films are an alternative to modified atmosphere storage $[28,110]$. As biopolymer layers reduce the oxygen uptake and carbon dioxide release, the respiratory and ripening processes inside the fruit are slowed down. Too thick or too impermeable films in combination with unfavourable environmental conditions could however induce a shift to anaerobic respiration inside the fruit as oxygen is depleted, which leads to fermentation and off-flavours [109, 118, 156].

\subsubsection{Modelling and experiments}

The aforementioned research on biopolymer layer characterisation is predominantly experimental, where the macroscopic film properties are determined $[38,70,114,118,120,123,158,159,160,161]$. Such typical properties are microstructure, thickness, mechanical properties (elastic modulus, tensile strength, glass transition temperature), barrier properties (effective diffusivity for moisture, gasses and volatile compounds), water sorption behaviour (sorption 
isotherm and hysteresis, optical properties (e.g. colour, transparency) and other functional aspects (antimicrobial activity, release of antioxidants). A non-exhaustive overview of the used techniques is given in Table 1. For each property of interest of the biopolymer layer, one or more commonly used characterisation techniques are presented. In addition to such characterisation, the layer efficacy is evaluated by measuring its various impacts on the product, such as for example product weight loss. A few of these quality aspects are presented in Table 1, together with their corresponding measurement technique. For edible films for food [162], this includes the physical and chemical effects (moisture loss, soluble solids content, titratable acids), retention of nutritional quality (vitamins, antioxidants), sensory quality (texture, taste, juiciness). Modelling work clearly lags behind, mainly due to the multitude of processes that need to be captured. Simple diffusion models based on Fick's law are commonplace, for example to determine the effective film diffusivity $[38,163]$.

\subsubsection{Advances}

An interesting recent development is the use of hydrogel-based films to alter and control the actual drying process of fresh-cut fruit [37, 157]. By packaging the fruit in a so-called "dehydrating film" prior to drying, the loss of volatile compounds can be strongly reduced, however at the cost of a lower fruit dehydration rate. For low-temperature drying, which is applied to preserve better the heat-sensitive compounds (e.g. vitamin C [164]), such packaging or coating techniques can be helpful in maintaining better product quality, even at low drying rates.

On another note, micro and nano-encapsulation are being explored to embed functional agents into films or coatings (Figure 12) $[28,29,89,110,165,166]$. Encapsulation increases the stability of the functional compounds for consumers (nutraceuticals, probiotics) and helps in controlling their release in a better way. This technique can also provide more effective ways to release antimicrobials, antioxidants (browning agents) or texture enhancers at the product surface. Edible films and coatings currently serve as carriers of functional compounds for both intact and fresh-cut fruit. However, the practical use of these encapsulation techniques is still rather scarce [110], most likely due to the associated cost and complexity during manufacturing. Note that such encapsulation techniques are also used to incorporate self-healing agents into coatings [167], as done recently to reduce crack formation on packaging boards. 


\subsubsection{Impact}

From the above, these biopolymer layers clearly have a large potential to enhance product quality of fresh and processed food in many ways. Currently, a lot of effort is directed towards micro-structuring these permeable layers as a way to obtain unique properties. A key aspect determining the performance of such tailored barriers is however rarely dealt with, namely how the barrier performance is affected by the specific conditions of the product and environment.

Typical examples were highlighted above, namely a different moisture barrier performance for intact or fresh-cut fruit, or how thick barriers can induce anaerobic respiration in fresh fruit depending on the internal and exterior gas composition. Changes in external process conditions, such as airflow or humidity, can thus be used to actively control and alter the barrier performance. The dehydration rate can, for example, be affected by triggering different states in which the barrier is in, namely the CDRP or the DDRP.

Several trade-offs are however present by which the same tailored layer can perform very well for some sub-surface and environmental conditions, but less adequately for others. The complex interplay in the product-barrierenvironment system will dictate the performance of the barrier for a specific application. A better insight in the interaction and transport between these domains is essential to engineer better biopolymer layers, to enhance product quality and to optimise processes towards large-scale industrial implementation.

\subsubsection{Future work}

Until now, biopolymer layers are investigated mostly using empirical approaches, where new recipes or ingredients are devised and combined with specific processing (drying) conditions. The success is evaluated based on the achieved material properties or functionalities of the layer, where an iterative procedure can be used to optimise the recipe and drying conditions. A deeper understanding of the nature of the obtained improvements and of their repercussions at the lower spatial scales is less often pursued, but is essential for removing some arbitrariness in designing better biobarriers. For some materials, including many foods, the complexity of the problem makes unveiling what happens extremely challenging. As an example, figuring out how coatings for fresh-cut fruit should work to provide optimal protection, by mimicking the behaviour of a fruit cuticle, is far from evident. First, the cuticle is already a semi- 
permeable membrane optimised by nature. Second, biobarriers are applied on wounded fruit tissue, which is not the case for a fruit cuticle [156].

Furthermore, barriers should not be manufactured to achieve certain properties but should rather be tailored to a certain application in order for them to achieve an optimal performance. Biopolymer layers could be used to enhance product quality during drying, for example by designing an edible film that keeps the fruit longer in the CDRP, which is typically very short. Even though the film will reduce the drying rate, the total drying process could be shortened as the CDRP is maintained for a longer time. Such films can also improve drying homogeneity within single fruits and between different fruits, and the resulting product quality. Enhancing drying processes by better balancing the transport in the product and in the boundary layer through the use of biobarriers is definitely an interesting future focus. Addressing the interactions between the product-barrier-environment system is currently hindered, amongst others, by incomplete material characterisation, for example over the entire water activity range.

Next to nano-encapsulation, direct incorporation of nanoparticles into films will also become more prevalent. Nanoparticles of different morphologies (platelets, tubes, fibres or particles) are already used in the packaging industry to design active and intelligent packaging, in which the biopolymers act as filler material $[168,169]$. These nanoparticles improve for example the barrier properties by affecting sorption sites or by altering the tortuosity of the transport pathways for water molecules. They also provide new ways to incorporate functional compounds in the film. A critical point related to the use of such nanomaterials is food safety. Safety issues involve the interaction of the particles with the filler matrix and their migration out of the packaging film, so leaching might be an issue [168].

Next to relying on experimental material synthesis, engineering such barriers should also rely more on computational modelling at lower scales $[10,170]$, for example atomistic simulations using molecular dynamics. With such simulations, material properties can be determined in-silico, for example the desorption and rehydration behaviour, since these properties are directly linked to the molecular structure, such as hydrocarbon length, cross-linking degree and the functional groups $[171,172]$. Thereby, material characterisation over a wide range of moisture contents is possible. These lower scale methods are particularly useful to investigate migration of nanomaterials out of their filler matrix [168]. Such computational engineering of biopolymer layers is still in its infancy and is complicated by the large variety of compositions and processing conditions. 


\section{Conclusion}

Understanding drying-related transport phenomena at interfaces between biomaterials and their environment often starts at the microscale level. The recent advances dealt with in this review include: (1) the impact of microscopic moisture sources, such as capillary pores or small droplets, but also micro-perforations in membranes such as stomata in leaves, or micro-cracks and lenticels in the fruit cuticle; (2) microstructural changes in cellular tissue during drying, including cell membrane breakage and cell collapse; (3) manufacturing of thin, permeable biopolymer layers, such as coatings or films, where drying is a critical step that determines the layer performance; (4) the use of such biopolymer layers as interfaces between product and environment, which fulfill a barrier function or are carriers for active compounds, such as nutraceuticals or self-healing components. A proper insight in the interactions at these product(barrier)-environment interfaces yields abundant unexplored ways for improving dehydration processes.

In this context, computational engineering will be challenged to keep up with the vast amount of advanced material science that is currently being performed. At the lower scales, multiscale approaches are required to upscale the findings and material properties at nano- and microscale levels to the macroscale (product level) by computational homogenisation $[173,174,175,176]$. At the continuum scale, intensified coupled modelling is critical. Apart from the hygro-thermo-mechanical behaviour of the product, also biochemical and biological processes in these complex biomaterials should be incorporated, as well as the conjugate exchange processes across the interface [10].

A better insight in drying at interfaces between biomaterials and their environment can be turned into a direct added value for industry. Commercial benefits are manifested by an increased product quality and shelf life, better product uniformity, reduced material waste or losses, and reduced energy consumption so a lower ecological footprint. Biobased films and coatings are an attractive medium to functionalise foods [89]. They also provide means to reuse industrial by-products as packaging, thereby reducing the use of synthetic petroleum-based materials. Currently, the industrial implementation of functional biopolymer layers is still hindered by upscaling difficulties from laboratory to full scale, practical implementation challenges and additional production and energy costs $[28,40,118]$. 


\section{Acknowledgements}

We acknowledge the support of the World Food System Center (WFSC) of ETH Zürich (www.worldfoodsystem.ethz.ch).

We also acknowledge the support of the Swiss National Science Foundation SNSF (project 200021_160047). 


\section{Tables}

Table 1. Several experimental techniques used to characterise biopolymer layers and their effects on product quality.

\begin{tabular}{|c|c|}
\hline Property of biopolymer layer & Method \\
\hline Glass transition and melting temperature & Differential scanning calorimetry \\
\hline Thickness & $\begin{array}{l}\text { Contact methods (micrometer) } \\
\text { Non-contact methods (e.g. optical microscopy, scanning electron microscope, confocal Raman } \\
\text { microspectrometry) }\end{array}$ \\
\hline Sorption isotherm & Dynamic vapour sorption (DVS) \\
\hline Antimicrobial effect & Activity of cell cultures/colonies \\
\hline Sensory analysis & Sensory tests on panel of tasters \\
\hline Microstructure & $\begin{array}{l}\text { Scanning electron microscopy } \\
\text { Atomic force microscopy } \\
\text { Rheological measurements } \\
\text { X-ray computer tomography }\end{array}$ \\
\hline $\begin{array}{l}\text { Molecular morphology (including degree of } \\
\text { crystallinity) }\end{array}$ & $\begin{array}{l}\text { Wide angle X-ray diffraction (WAXS) } \\
\text { Small angle X-ray diffraction (SAXS) }\end{array}$ \\
\hline Moisture diffusivity & $\begin{array}{l}\text { From drying curve, based on Fick's law } \\
\text { Wet cup/dry cup tests in environmental chambers or in DVS }\end{array}$ \\
\hline Gas diffusivity & $\begin{array}{l}\text { From mass transport, based on Fick's law } \\
\text { Gas transmission rate testing in environmental chambers or in DVS }\end{array}$ \\
\hline $\begin{array}{l}\text { Tensile strength \& elongation/strain at } \\
\text { break, elastic modulus }\end{array}$ & Tensile test \\
\hline Swelling behaviour & $\begin{array}{l}\text { Swelling test } \\
\text { X-ray computer tomography }\end{array}$ \\
\hline Effect on product (e.g. fruit) & Method \\
\hline Total soluble solids content & Digital refractometer \\
\hline Colour & Colorimeter \\
\hline Weight loss & Gravimetrically \\
\hline
\end{tabular}




\section{Figure captions}

Figure 1. Transport processes inside porous material (product) and exchange processes at product-environment interfaces (adapted from [10]), with a close-up of the air-material interface for a developing boundary layer (U = air speed, $p_{v}=$ vapour pressure, $\infty=$ free-stream value). The environment includes the surrounding air (depicted on the right) as well as contact with solid or porous materials, for example process equipment or other products.

Figure 2. (a) Surfaces that are only partially covered with moisture sources at the product-environment interface; (b) Dehydration stages of a single (non-deformable) pore ( $p_{c}$ : capillary pressure, $\gamma_{L v}$ : surface tension between liquid and vapour, $R$ : radius of curvature of the meniscus, r: pore radius, $\theta$ : contact angle).

Figure 3. Dehydration of (a) cellular tissue, such as fruit, (b) a hydrogel (adapted from [101], $R$ : radius of curvature of the meniscus, which is equal for all pores exposed to the same capillary pressure).

Figure 4. Dehydration of biopolymer layers (a) during a-priori manufacturing by applying it on a substrate and drying it and (b) applied (coated) directly onto the product.

Figure 5. (a) Schematic of water vapour concentration contours, in blue dash lines, in the boundary layer over a surface with discretely-distributed moisture sources (indicated in blue) with indication of $d, \delta_{v S L}$ and laminar and turbulent regions in the boundary layer ( $d=$ size of the sources, $\delta_{v s L}=$ thickness of the viscous sublayer). (b) Illustration of evaporation from discrete stomata from a leaf via the boundary layer (from [41]). A single water vapour concentration isocontour is shown, coloured according to air speed, where the air speeds in a horizontal and vertical centreplane are also shown. (c) Mass flow rate as a function of the surface coverage ratio $\left(C R=A_{\text {eff }} / A\right)$ for different 
$d / \delta_{v S L}$ ratios (from [18]), based on the analytical equation of Schlünder [42], which is also given. The mass flow rate form a partially covered surface $\left(G_{c, w}\right)$ is scaled with that of a surface with a coverage ratio of $100 \%\left(G_{c, w, 100 \%}\right)$. Points 1, 2 and 3 indicate different stages in the drying process of droplets.

Figure 6. Cellular water transport pathways (adjusted from [177]).

Figure 7. (a) Dried apples slice imaged from scanning electronic microscopy [81]. (b) Apple parenchyma cells of fresh tissue imaged with X-ray tomography and segmented for visualisation [73].

Figure 8. (a) Different stages of dehydration of a single cell. (b) Osmotic dehydration of an isolated apple cell (from [61]).

Figure 9. Examples of hygro-micromechanical models of cellular tissue. (a) Fresh and partially dehydrated tissue [58].

(b) Deformed cellular structure using SPH-DEM [78] (smoothed particle hydrodynamics-discrete element method, published by The Royal Society of Chemistry).

Figure 10. Typical sol-gel process for a hydrogel.

Figure 11. Field emission scanning electron microscopy (FESEM) images of a hierarchical porous structure (reprinted (adapted) with permission from [136]. Copyright (2011) American Chemical Society). In the sequence from left (a) to right (d), the red rectangles indicate the areas magnified in the right image. 
Figure 12. Illustration of multilayer coating of intact or minimally-processed fruit by layer-by-layer deposition (adapted from [117]).

Figure 13. Sorption and desorption isotherm for a gelatine film (data from [121]).

Figure 14. Moisture permeability (or water vapour permeability WVP): (a) for many different films (each point represents a specific case), as a function of the relative humidity difference that is imposed over the film (data from $[113,178]) ;(b, c)$ for three films (data from [155]) as a function of (b) several relative humidity differences that are imposed over each of the films, with the $\mathrm{RH}$ at one side of the film being $0 \%$ for all cases, (c) the corresponding average capillary pressure within the film (from (b), log-log scale), calculated from the average RH in the film.

Figure 15. Illustration of possible impact of humidity of the product on the moisture permeability of permeable biopolymer layers, for the example of fresh-cut (left) and intact fruit (right): (a) schematic of cross section; (b) permeability as a function of capillary pressure (log-log scale) for a typical porous material [179], with illustration of the water activity range in the biopolymer layer in blue.

\section{References}

[1] Mujumdar, A.S. Handbook of Industrial Drying, Fourth. ed 2014. CRC Press, Taylor \& Francis Group, Boca Raton, USA.

[2] Dev, S.R.S.; Raghavan, V.G.S. Advancements in drying techniques for food, fiber, and fuel. Drying Technology 2012, 30, 1147-1159.

[3] Mujumdar, A.S.; Huang, L.-X. Global R\&D needs in drying. Drying Technology 2007, 25, 647-658.

[4] Jangam, S.V. An overview of recent developments and some R\&D challenges related to drying of foods. Drying Technology 2011, 29, 1343-1357. 
[5] Chou, S.K.; Chua, K.J. New hybrid drying technologies for heat sensitive foodstuffs. Trends in Food Science \& Technology 2001, 12, 359-369.

[6] Liu, X.; Lee, D.-J. Some recent research and development advances in drying technologies: product perspective. Drying Technology 2015, 33, 1339-1349.

[7] Zhang, M.; Chen, H.; Mujumdar, A.S.; Tang, J.; Miao, S.; Wang, Y. Recent developments in high-quality drying of vegetables, fruits and aquatic products, Critical Reviews in Food Science and Nutrition 2015.

[8] Defraeye, T.; Blocken, B.; Derome, D.; Nicolai, B.; Carmeliet, J. Convective heat and mass transfer modelling at airporous material interfaces: Overview of existing methods and relevance. Chemical Engineering Science 2012, 74, 49-58.

[9] Marra, F.; De Bonis, M. V.; Ruocco, G. Combined microwaves and convection heating: A conjugate approach. Journal of Food Engineering 2010, 97, 31-39.

[10] Defraeye, T. Advanced computational modelling for drying processes - a review. Applied Energy 2014, 131, 323344.

[11] Halder, A.; Datta, A.K. Surface heat and mass transfer coefficients for multiphase porous media transport models with rapid evaporation. Food and Bioproducts Processing 2012, 90, 475-490.

[12] Defraeye, T.; Blocken, B.; Carmeliet, J. CFD analysis of convective heat transfer at the surfaces of a cube immersed in a turbulent boundary layer. International Journal of Heat and Mass Transfer 2010, 53, 297-308.

[13] Defraeye, T.; Verboven, P.; Ho, Q.T.; Nicolai, B. Convective heat and mass exchange predictions at leaf surfaces: Applications, methods and perspectives. Computers and Electronics in Agriculture 2013, 96, $180-201$.

[14] Schuepp, P.H. Leaf boundary layers. New Phytologist 1993, 477-507.

[15] Belhamri, A.; Fohr, J.-P. Heat and mass transfer along a wetted porous plate in an air stream. AIChE Journal 1996, $42,1833-1843$. 
[16] Carmeliet, J.; Hens, H.; Roels, S.; Adan, O.; Brocken, H.; Cerny, R.; Pavlik, Z.; Hall, C.; Kumaran, K.; Pel, L.

Determination of the liquid water diffusivity from transient moisture transfer experiments. Journal of Building Physics $2004,27,277-305$.

[17] Shahraeeni, E.; Lehmann, P.; Or, D. Coupling of evaporative fluxes from drying porous surfaces with air boundary layer: Characteristics of evaporation from discrete pores. Water Resources Research 2012, 48, 1-15.

[18] Defraeye, T.; Verboven, P.; Derome, D.; Carmeliet, J.; Nicolai, B. Stomatal transpiration and droplet evaporation on leaf surfaces by a microscale modelling approach. International Journal of Heat and Mass Transfer 2013, 65, 180-191.

[19] Assouline, S.; Narkis, K.; Or, D. Evaporation suppression from water reservoirs: Efficiency considerations of partial covers. Water Resources Research 2011, 47, 1-8.

[20] Veraverbeke, E.A.; Verboven, P.; Van Oostveldt, P.; Nicolaï, B.M. Prediction of moisture loss across the cuticle of apple (Malus sylvestris subsp. mitis (Wallr.)) during storage: Part 2. Model simulations and practical applications. Postharvest Biology and Technology 2003, 30, 89-97.

[21] Yu, Y.; Zhu, H.; Frantz, J.M.; Reding, M.E.; Chan, K.C.; Ozkan, H.E. Evaporation and coverage area of pesticide droplets on hairy and waxy leaves. Biosystems Engineering 2009, 104, 324-334.

[22] Xu, L.; Zhu, H.; Ozkan, H.E.; Thistle, H.W. Evaporation rate and development of wetted area of water droplets with and without surfactant at different locations on waxy leaf surfaces. Biosystems Engineering 2010, 106, 58-67.

[23] Defraeye, T.; Aregawi, W.; Saneinejad, S.; Vontobel, P.; Lehmann, E.; Carmeliet, J.; Verboven, P.; Derome, D.; Nicolai, B. Novel application of neutron radiography to forced convective drying of fruit tissue. Food and Bioprocess Technology 2012, 6, 3353-3367.

[24] Achanta, S.; Okos, M.R.; Cushman, J.H.; Kessler, D.P. Moisture transport in shrinking gels during saturated drying. AlChE Journal 1997, 43, 2112-2122.

[25] Tao, T.; Peng, X.F.; Lee, D.J. Structure of crack in thermally dried sludge cake. Drying Technology 2006, 23, 15551568. 
[26] Bai, Y.; Rahman, M.S.; Perera, C.O.; Smith, B.; Melton, L.D. Structural changes in apple rings during convection airdrying with controlled temperature and humidity. Journal of Agricultural and Food Chemistry 2002, 50, 3179-3185.

[27] Augst, A.D.; Kong, H.J.; Mooney, D.J. Alginate hydrogels as biomaterials. Macromolecular Bioscience 2006, 6, 623633.

[28] Dhall, R.K. Advances in edible coatings for fresh fruits and vegetables: a review. Critical Reviews in Food Science and Nutrition 2013, 53, 435-450.

[29] Vargas, M.; Pastor, C.; Chiralt, A.; McClements, D.J.; González-Martínez, C. Recent advances in edible coatings for fresh and minimally processed fruits. Critical Reviews in Food Science and Nutrition 2008, 48, 496-511.

[30] Embuscado, M.E.; Huber, K.C. Edible films and coatings for food applications 2009. Springer, New York.

[31] Wandera, D.; Wickramasinghe, S.R.; Husson, S.M. Stimuli-responsive membranes. Journal of Membrane Science $2010,357,6-35$.

[32] Peppas, N.A.; Hilt, J.Z.; Khademhosseini, A.; Langer, R. Hydrogels in biology and medicine: From molecular principles to bionanotechnology. Advanced Materials 2006, 18, 1345-1360.

[33] Liu, L.S.; Kost, J.; Yan, F.; Spiro, R.C. Hydrogels from biopolymer hybrid for biomedical, food, and functional food applications. Polymers 2012, 4, 997-1011.

[34] Choi, S.W.; Xie, J.; Xia, Y. Chitosan-based inverse opals: Three-dimensional scaffolds with uniform pore structures for cell culture. Advanced Materials 2009, 21, 2997-3001.

[35] Liebi, M.; Kuster, S.; Kohlbrecher, J.; Ishikawa, T.; Fischer, P.; Walde, P.; Windhab, E.J. Magnetically enhanced bicelles delivering switchable anisotropy in optical gels. ACS Applied Materials and Interfaces 2014, 6, 1100-1105.

[36] Romanazzi, G.; Feliziani, E.; Baños, S.B.; Sivakumar, D. Shelf life extension of fresh fruit and vegetables by chitosan treatment. Critical Reviews in Food Science and Nutrition 2015, 00-00.

[37] Laurienzo, P.; Stasio, M. Di; Malinconico, M.; Volpe, M.G. De-hydration of apples by innovative bio-films drying. Journal of Food Engineering 2010, 97, 491-496. 
[38] Wong, T.W.; Ashikin, W.H.N.S.; Law, C.L. Evaporation and diffusion transport properties and mechanical properties of alginate dried film. Drying Technology 2014, 32, 117-125.

[39] Palzer, S.; Dubois, C.; Gianfrancesco, A. Generation of product structures during drying of food products. Drying Technology 2012, 30, 97-105.

[40] Rossman, J.M. Commercial manufacture of edible films, in: Embuscado, M.E., Huber, K.C. (Eds.), Edible Films and Coatings for Food Applications 2009. Springer, pp. 367-390.

[41] Defraeye, T.; Derome, D.; Verboven, P.; Carmeliet, J.; Nicolai, B. Cross-scale modelling of transpiration from stomata via the leaf boundary layer. Annals of Botany 2014, 114, 711-723.

[42] Schlünder, E.U. On the mechanism of the constant drying rate. Chemical Engineering Science 1988, 43, 2685-2688.

[43] Haseba, T. Mass transfer across the boundary layer on plant leaves (1): Preliminary study of water-vapor transfer from a leaf-like flat plate with separated evaporation sources. Journal of Agricultural Meteorology 1974, 30, 45-55.

[44] Leclerc, M.Y.; Schuepp, P.H.; Thurtell, G.W. Electrochemical simulations of mass transfer from isolated wet spots and droplets on realistic fluttering leaves. Boundary-Layer Meteorology 1986, 34, 399-410.

[45] Suzuki, M.; Maeda, S. On the mechanism of drying of granular beds. Journal of Chemical Engineering of Japan 1968, 1, 26-31.

[46] Lehmann, P.; Or, D. Effect of wetness patchiness on evaporation dynamics from drying porous surfaces. Water Resources Research 2013, 49, 8250-8262.

[47] Haghighi, E.; Shahraeeni, E.; Lehmann, P.; Or, D. Evaporation rates across a convective air boundary layer are dominated by diffusion. Water Resources Research 2013, 49, 1602-1610.

[48] Haghighi, E.; Or, D. Evaporation from porous surfaces into turbulent airflows: Coupling eddy characteristics with pore scale vapor diffusion. Water Resources Research 2013, 49, 8432-8442.

[49] Aminzadeh, M.; Or, D. Temperature dynamics during nonisothermal evaporation from drying porous surfaces. Water Resources Research 2013, 49, 7339-7349. 
[50] Gonçalves, T.D.; Brito, V.; Pel, L. Water vapor emission from rigid mesoporous materials during the constant drying rate period. Drying Technology 2012, 30, 462-474.

[51] Assouline, S.; Narkis, K.; Or, D. Evaporation from partially covered water surfaces. Water Resources Research 2010, $46,1-12$.

[52] Defraeye, T.; Herremans, E.; Verboven, P.; Carmeliet, J.; Nicolai, B. Convective heat and mass exchange at surfaces of horticultural products: A microscale CFD modelling approach. Agricultural and Forest Meteorology 2012, 162-163, 71-84.

[53] Cannon, J.N.; Krantz, W.B.; Kreith, F.; Naot, D. A study of transpiration from porous flat plates simulating plant leaves. International Journal of Heat and Mass Transfer 1979, 22, 469-483.

[54] Kelly-Zion, P.L.; Pursell, C.J.; Hasbamrer, N.; Cardozo, B.; Gaughan, K.; Nickels, K. Vapor distribution above an evaporating sessile drop. International Journal of Heat and Mass Transfer 2013, 65, 165-172.

[55] Dehaeck, S.; Rednikov, A.; Colinet, P. Vapour-based interferometric measurement of local evaporation rate and interfacial temperature of evaporating droplets. Langmuir 2014, 30, 2002-2008.

[56] Brinker, C.; Scherer, G. Sol-gel science: The physics and chemistry of sol-gel processing. 1990, Academic Press Limited.

[57] Mosthaf, K.; Helmig, R.; Or, D. Modeling and analysis of evaporation processes from porous media on the REV scale. Water Resources Research 2014 50, 1059-1079.

[58] Fanta, S.W.; Abera, M.K.; Aregawi, W.; Ho, Q.T.; Verboven, P.; Carmeliet, J.; Nicolai, B.M. Microscale modeling of coupled water transport and mechanical deformation of fruit tissue during dehydration. Journal of Food Engineering $2014,124,86-96$.

[59] Lewicki, P.P.; Pawlak, G. Effect of drying on microstructure of plant tissue. Drying Technology 2003, 21, 657-683.

[60] Mayor, L.; Sereno, A.M. Modelling shrinkage during convective drying of food materials: a review. Journal of Food Engineering 2004, 61, 373-386. 
[61] Seguí, L.; Fito, P.J.; Fito, P. Analysis of structure-property relationships in isolated cells during OD treatments. Effect of initial structure on the cell behaviour. Journal of Food Engineering 2010, 99, 417-423.

[62] Halder, A.; Datta, A.K.; Spanswick, R.M. Water transport in cellular tissues during thermal processing. AIChE Journal $2011,57,2574-2588$.

[63] Karunasena, H.C.P.; Hesami, P.; Senadeera, W.; Gu, Y.T.; Brown, R.J.; Oloyede, A. Scanning electron microscopic study of microstructure of gala apples during hot air drying. Drying Technology 2014, 32, 455-468.

[64] Prothon, F.; Ahrné, L.; Sjöholm, I. Mechanisms and prevention of plant tissue collapse during dehydration: a critical review. Critical reviews in food science and nutrition 2003, 43, 447-479.

[65] Valle, J.M.; Cuadros, T.R.M.; Aguilera, J.M. Glass transitions and shrinkage during drying and storage of osmosed apple pieces. Food Research International 1998, 31, 191-204.

[66] Gulati, T.; Datta, A.K. Mechanistic understanding of case-hardening and texture development during drying of food materials. Journal of Food Engineering 2015, 166, 119-138.

[67] Bonazzi, C.; Dumoulin, E. Quality changes in food materials as influenced by drying processes, in: Tsotsas, E., Mujumdar, A.S. (Eds.), Modern Drying Technology - Product Quality and Formulation 2011. Wiley-VHC Verlag GmbH, Weinheim, Germany, pp. 1-20.

[68] Vega-Gálvez, A.; Ah-Hen, K.; Chacana, M.; Vergara, J.; Martínez-Monzó, J.; García-Segovia, P.; Lemus-Mondaca, R.; Di Scala, K. Effect of temperature and air velocity on drying kinetics, antioxidant capacity, total phenolic content, colour, texture and microstructure of apple (var. Granny Smith) slices. Food Chemistry 2012, 132, 51-59.

[69] Vega-Gálvez, A.; Uribe, E.; Perez, M.; Tabilo-Munizaga, G.; Vergara, J.; Garcia-Segovia, P.; Lara, E.; Di Scala, K. Effect of high hydrostatic pressure pretreatment on drying kinetics, antioxidant activity, firmness and microstructure of Aloe vera (Aloe barbadensis Miller) gel. LWT - Food Science and Technology 2011, 44, 384-391.

[70] Niamnuy, C.; Devahastin, S.; Soponronnarit, S. Some recent advances in microstructural modification and monitoring of foods during drying: A review. Journal of Food Engineering 2014, 123, 148-156. 
[71] Moreira, R.; Chenlo, F.; Chaguri, L.; Mayor, L. Analysis of chestnut cellular tissue during osmotic dehydration, air drying, and rehydration processes. Drying Technology 2010, 29, 10-18.

[72] Dotto, G.L.; de Souza, V.C.; de Moura, J.M.; de Moura, C.M.; de Almeida Pinto, L.A. Influence of drying techniques on the characteristics of chitosan and the quality of biopolymer films. Drying Technology 2011, 29, 1784-1791.

[73] Herremans, E.; Verboven, P.; Bongaers, E.; Estrade, P.; Verlinden, B.E.; Wevers, M.; Hertog, M.L.A.T.M.; Nicolai, B. Characterisation of "Braeburn" browning disorder by means of X-ray micro-CT. Postharvest Biology and Technology $2013,75,114-124$.

[74] Herremans, E.; Melado-Herreros, A.; Defraeye, T.; Verlinden, B.; Hertog, M.; Verboven, P.; Val, J.; Fernández-Valle, M.E.; Bongaers, E.; Estrade, P.; Wevers, M.; Barreiro, P.; Nicolaï, B.M. Comparison of X-ray CT and MRI of watercore disorder of different apple cultivars. Postharvest Biology and Technology 2014, 87, 42-50.

[75] Léonard, A.; Blacher, S.; Nimmol, C.; Devahastin, S. Effect of far-infrared radiation assisted drying on microstructure of banana slices: An illustrative use of X-ray microtomography in microstructural evaluation of a food product. Journal of Food Engineering 2008, 85, 154-162.

[76] Fanta, S.W.; Abera, M.K.; Ho, Q.T.; Verboven, P.; Carmeliet, J.; Nicolai, B.M. Microscale modeling of water transport in fruit tissue. Journal of Food Engineering 2013, 118, 229-237.

[77] Abera, M.K.; Fanta, S.W.; Verboven, P.; Ho, Q.T.; Carmeliet, J.; Nicolai, B.M. Virtual fruit tissue generation based on cell growth modelling. Food and Bioprocess Technology 2013, 6, 859-869.

[78] Karunasena, H.C.P.; Senadeera, W.; Brown, R.J.; Gu, Y.T. A particle based model to simulate microscale morphological changes of plant tissues during drying. Soft matter 2014, 10, 5249-5268.

[79] Karunasena, H.C.P.; Brown, R.J.; Gu, Y.T.; Senadeera, W. Application of meshfree methods to numerically simulate microscale deformations of different plant food materials during drying. Journal of Food Engineering 2015, 146, 209226.

[80] Van Liedekerke, P.; Ghysels, P.; Tijskens, E.; Samaey, G.; Roose, D.; Ramon, H. Mechanisms of soft cellular tissue bruising. A particle based simulation approach. Soft Matter 2011, 7, 3580-3591. 
[81] Askari, G.R.; Emam-Djomeh, Z.; Mousavi, S.M. An investigation of the effects of drying methods and conditions on drying characteristics and quality attributes of agricultural products during hot air and hot air/microwave-assisted dehydration. Drying Technology 2009, 27, 831-841.

[82] Witrowa-Rajchert, D.; Rzaca, M. Effect of drying method on the microstructure and physical properties of dried apples. Drying Technology 2009, 27, 903-909.

[83] Mcminn, W.A.M.; Magee, T.R.A. Principles, methods and applications of the convective drying of foodstuffs. Food and Bioproducts Processing 1999, 77, 175-193.

[84] Ben Mabrouk, S.; Benali, E.; Oueslati, H. Experimental study and numerical modelling of drying characteristics of apple slices. Food and Bioproducts Processing 2012, 90, 719-728.

[85] Velić, D.; Planinić, M.; Tomas, S.; Bilić, M. Influence of airflow velocity on kinetics of convection apple drying. Journal of Food Engineering 2004, 64, 97-102.

[86] Caurie, M. Hysteresis phenomenon in foods. International Journal of Food Science \& Technology 2007, 42, 45-49.

[87] Udomkun, P.; Argyropoulos, D.; Nagle, M.; Mahayothee, B.; Müller, J. Sorption behaviour of papayas as affected by compositional and structural alterations from osmotic pretreatment and drying. Journal of Food Engineering 2015, 157, $14-23$.

[88] Acevedo, N.C.; Briones, V.; Buera, P.; Aguilera, J.M. Microstructure affects the rate of chemical, physical and color changes during storage of dried apple discs. Journal of Food Engineering 2008, 85, 222-231.

[89] Betoret, E.; Betoret, N.; Vidal, D.; Fito, P. Functional foods development: Trends and technologies. Trends in Food Science \& Technology 2011, 22, 498-508.

[90] Gong, Z.; Gao, L.; An, J.; Zhang, M.; Mujumdar, A.S.; Sun, J. Effects of predrying and vacuum impregnation with nano-calcium carbonate solution on strawberries, carrots, corn, and blueberries. Drying Technology 2009, 28, 36-41.

[91] Seguí, L.; Fito, P.J.; Fito, P. Understanding osmotic dehydration of tissue structured foods by means of a cellular approach. Journal of Food Engineering 2012, 110, 240-247. 
[92] Nowacka, M.; Wiktor, A.; Śledź, M.; Jurek, N.; Witrowa-Rajchert, D. Drying of ultrasound pretreated apple and its selected physical properties. Journal of Food Engineering 2012, 113, 427-433.

[93] Rodríguez, Ó.; Santacatalina, J. V.; Simal, S.; Garcia-Perez, J. V.; Femenia, A.; Rosselló, C. Influence of power ultrasound application on drying kinetics of apple and its antioxidant and microstructural properties. Journal of Food Engineering 2014, 129, 21-29.

[94] Santacatalina, J. V.; Rodríguez, O.; Simal, S.; Cárcel, J.A.; Mulet, A.; García-Pérez, J. V. Ultrasonically enhanced lowtemperature drying of apple: Influence on drying kinetics and antioxidant potential. Journal of Food Engineering 2014, $138,35-44$.

[95] Schossler, K.; Thomas, T.; Knorr, D. Modification of cell structure and mass transfer in potato tissue by contact ultrasound. Food Research International 2012, 49, 425-431.

[96] Mothibe, K.J.; Zhang, M.; Nsor-Atindana, J.; Wang, Y.-C. Use of ultrasound pretreatment in drying of fruits: drying Rates, quality attributes, and shelf life extension. Drying Technology 2011, 29, 1611-1621.

[97] Kowalski, S.J.; Mierzwa, D. Ultrasound-assisted convective drying of biological materials. Drying Technology 2015, 33, 1601-1613.

[98] Kowalski, S.J.; Pawłowski, A. Intensification of apple drying due to ultrasound enhancement. Journal of Food Engineering 2015, 156, 1-9.

[99] Defraeye, T.; Blocken, B.; Carmeliet, J. Analysis of convective heat and mass transfer coefficients for convective drying of a porous flat plate by conjugate modelling. International Journal of Heat and Mass Transfer 2012, 55, $112-124$.

[100] Tang, T.D.; Pauken, M.T.; Jeter, S.M.; Abdel-Khalik, S.I. On the use of monolayers to reduce evaporation from stationary water pools. Journal of Heat Transfer 1993, 115, 209.

[101] Scherer, G.W. Theory of Drying. Journal of the American Ceramic Society 1990, 73, 3-14.

[102] Kowalski, S.J.; Kulczynski, K. Acoustic emission monitoring of fracture in dryed kaolin-clay processed with surfactant water solution. Ceramic Materials 2013, 65, 235-238. 
[103] Bengtsson, G.B.; Rahman, M.S.; Stanley, R.A.; Perera, C.O. Apple rings as a model for fruit drying behavior : effects of surfactant and reduced osmolality reveal biological mechanisms. Food Engineering and Physical Properties 2003, 68, 563-570.

[104] ASTM. American Society for Testing and Materials: Standard Terminology Relating to Plastics (ASTM D883 - 12) 2008.

[105] Farris, S.; Schaich, K.M.; Liu, L.; Piergiovanni, L.; Yam, K.L. Development of polyion-complex hydrogels as an alternative approach for the production of bio-based polymers for food packaging applications: a review. Trends in Food Science and Technology 2009, 20, 316-332.

[106] Mahajan, P. V; Caleb, O.J.; Singh, Z.; Watkins, C.B.; Geyer, M. Postharvest treatments of fresh produce. Philosophical Transactions of the Royal Society A 2014, 372, 20130309.

[107] Zou, Q.; Opara, U.L.; McKibbin, R. A CFD modeling system for airflow and heat transfer in ventilated packaging for fresh foods: Il. Computational solution, software development, and model testing. Journal of Food Engineering 2006, 77, 1048-1058.

[108] Umaraw, P.; Verma, A.K. Comprehensive review on application of edible film on meat and meat products: An ecofriendly approach, Critical Reviews in Food Science and Nutrition 2015.

[109] Pavlath, A.E.; Orts, W. Edible Films and Coatings: Wy, What, and How?, in: Embuscado, M., Huber, C. (Eds.), Edible Films and Coatings for Food Applications 2009. Springer, pp. 1-23.

[110] Rojas-Graü, M.A.; Soliva-Fortuny, R.; Martín-Belloso, O. Edible coatings to incorporate active ingredients to freshcut fruits: a review. Trends in Food Science and Technology 2009, 20, 438-447.

[111] Synowiec, A.; Gniewosz, M.; Kraśniewska, K.; Chlebowska-Śmigiel, A.; Przybył, J.; Bączek, K.; Węglarz, Z. Effect of meadowsweet flower extract-pullulan coatings on rhizopus rot development and postharvest quality of cold-stored red peppers. Molecules 2014, 19, 12925-12939.

[112] Rodriguez, A.; García, M.A.; Campañone, L.A. Experimental study of the application of edible coatings in pumpkin sticks submitted to osmotic dehydration. Drying Technology 2015, 150717130829009. 
[113] Debeaufort, F.; Voilley, A. Lipid-based edible films and coatings, in: Embuscado, M.E., Huber, C. (Eds.), Edible Films and Coatings for Food Applications 2009di. Springer, pp. 135-168.

[114] Thakhiew, W.; Waisayawan, P.; Devahastin, S. Comparative evaluation of mathematical models for release of antioxidant from chitosan films prepared by different drying methods. Drying Technology 2011, 29, 1396-1403.

[115] Quezada-Gallo, J.-A. Delivery of food additives and antimicrobials using edible films and coatings, in: Embuscado, M.E., Huber, K.C. (Eds.), Edible Films and Coatings for Food Applications 2009. Springer, pp. 315-333.

[116] Martín-Belloso, O.; Rojas-Graü, A.; Soliva-Fortuny, R. Delivery of flavor and active ingredients using edible films and coatings, in: Embuscado, M.E., Huber, K.C. (Eds.), Edible Films and Coatings for Food Applications 2009. Springer, pp. 295-313.

[117] Weiss, J.; Takhistov, P.; McClements, D.J. Functional materials in food nanotechnology. Journal of Food Science 2006, 71, 107-116.

[118] Skurtys, O.; Acevedo, C.; Pedreschi, F.; Enrione, J.; Osorio, F.; Aguilera, J.M. Food hydrocolloid edible films and coatings, in: Hollingworth, C.S. (Ed.), Food Hydrocolloids: Characteristics, Properties and Structures 2010. Nova Science Publishers, pp. 41-80.

[119] Wang, B.; Zhang, W.; Zhang, W.; Mujumdar, A.S.; Huang, L. Progress in drying technology for nanomaterials. Drying Technology 2005, 23, 7-32.

[120] Silva, M.A. Da; Bierhalz, A.C.K.; Kieckbusch, T.G. Influence of drying conditions on physical properties of alginate films. Drying Technology 2012, 30, 72-79.

[121] Badii, F.; MacNaughtan, W.; Mitchell, J.R.; Farhat, I.A. The effect of drying temperature on physical properties of thin gelatin films. Drying Technology 2014, 32, 30-38.

[122] Khalloufi, S.; Almeida-Rivera, C.; Janssen, J.; Van-Der-Vaart, M.; Bongers, P. Mathematical model for simulating the springback effect of gel matrixes during drying processes and its experimental validation. Drying Technology 2011, 29, 1972-1980. 
[123] Moreira, R.; Chenlo, F.; Torres, M.D.; Silva, C.; Prieto, D.M.; Sousa, A.M.M.; Hilliou, L.; Gonçalves, M.P. Drying kinetics of biofilms obtained from chestnut starch and carrageenan with and without glycerol. Drying Technology 2011, 29, 1058-1065.

[124] Escalona, I.; Jomaa, W.; Olivera-Fuentes, C.; Crine, M.; Léonard, A. Convective drying of gels: Comparison between simulated and experimental moisture profiles obtained by X-ray microtomography. Drying Technology 2010, 28, 644650.

[125] Schmid, M.; Eib, S.; Reinelt, M. Modeling, simulation, and experimental validation of drying and denaturation behavior of whey protein isolate-based coatings. Drying Technology 2015, 33, 1382-1395.

[126] Patra, S.; Bal, D.K.; Ganguly, S. Diffusion of moisture from hydrogel scaffold with induced porosity from selfassembled bubbles. Drying Technology 2015, 33, 336-345.

[127] Rassis, D.; Nussinovitch, A.; Saguy, I.S. Tailor-made porous solid foods. International Journal of Food Science and Technology 1997, 32, 271-278.

[128] Schrader, G.W.; Litchfield, J.B. Moisture profiles in a model food gel during drying: measurement using magnetic resonance imaging and evaluation of the Fickian model, Drying Technology 1992, 10, 295-332.

[129] Ruiz-Cabrera, M.A.; Foucat, L.; Bonny, J.M.; Renou, J.P.; Daudin, J.D. Assessment of water diffusivity in gelatine gel from moisture profiles. I - Non-destructive measurement of 1D moisture profiles during drying from 2D nuclear magnetic resonance images. Journal of Food Engineering 2005, 68, 209-219.

[130] Li, J.; Cabane, B.; Sztucki, M.; Gummel, J.; Goehring, L. Drying dip-coated colloidal films. Langmuir 2012, 28, 200208.

[131] Xiao, Q.; Gu, X.; Tan, S. Drying process of sodium alginate films studied by two-dimensional correlation ATR-FTIR spectroscopy. Food Chemistry 2014, 164, 179-184.

[132] Nijdam, J.; Kachel, S.; Scharfer, P.; Schabel, W.; Kind, M. Effect of diffusion on component segregation during drying of aqueous solutions containing protein and sugar. Drying Technology 2015, 33, 288-300. 
[133] Li, W.; Walz, J.Y. Porous nanocomposites with integrated internal domains: application to separation membranes. Scientific Reports 2014, 4, 1-7.

[134] Li, Y.; Fu, Z.-Y.; Su, B.-L. Hierarchically structured porous materials for energy conversion and storage. Advanced Functional Materials 2012, 22, 4634-4667.

[135] Dorin, R.M.; Sai, H.; Wiesner, U. Hierarchically porous materials from block copolymers. Chemistry of Materials $2014,26,339-347$.

[136] Studart, A.R.; Studer, J.; Xu, L.; Yoon, K.; Shum, H.C.; Weitz, D.A. Hierarchical porous materials made by drying complex suspensions. Langmuir 2011, 27, 955-964.

[137] Borisova, A.; De Bruyn, M.; Budarin, V.L.; Shuttleworth, P.S.; Dodson, J.R.; Segatto, M.L.; Clark, J.H. A sustainable freeze-drying route to porous polysaccharides with tailored hierarchical meso- and macroporosity. Macromolecular Rapid Communications 2015, 10.1002/marc.201400680.

[138] Zhang, R.; Cao, Y.; Li, P.; Zang, X.; Sun, P.; Wang, K.; Zhong, M. Three-dimensional porous graphene sponges assembled with the combination of surfactant and freeze drying. Nano Research 2014, 7, 1477-1487.

[139] Phadke, A.; Zhang, C.; Arman, B.; Hsu, C.-C.; Mashelkar, R.A.; Lele, A.K.; Tauber, M.J.; Arya, G.; Varghese, S. Rapid self-healing hydrogels. Proceedings of the National Academy of Sciences 2012, 109, 4383-4388.

[140] Liu, L.; Liu, C.K.; Fishman, M.L.; Hicks, K.B. Composite films from pectin and fish skin gelatin or soybean flour protein. Journal of Agricultural and Food Chemistry 2007, 55, 2349-2355.

[141] Farris, S.; Schaich, K.M.; Liu, L.; Cooke, P.H.; Piergiovanni, L.; Yam, K.L. Gelatin-pectin composite films from polyioncomplex hydrogels. Food Hydrocolloids 2011, 25, 61-70.

[142] Shukla, A.; Fleming, K.E.; Chuang, H.F.; Chau, T.M.; Loose, C.R.; Stephanopoulos, G.N.; Hammond, P.T. Controlling the release of peptide antimicrobial agents from surfaces. Biomaterials 2010, 31, 2348-2357.

[143] Mikkonen, K.S.; Parikka, K.; Ghafar, A.; Tenkanen, M. Prospects of polysaccharide aerogels as modern advanced food materials. Trends in Food Science and Technology 2013, 34, 124-136. 
[144] Valentin, R.; Molvinger, K.; Viton, C.; Domard, A.; Quignard, F. From hydrocolloids to high specific surface area porous supports for catalysis. Biomacromolecules 2005, 6, 2785-2792.

[145] Quignard, F.; Valentin, R.; Di Renzo, F. Aerogel materials from marine polysaccharides. New Journal of Chemistry $2008,32,1300-1310$.

[146] Laurienzo, P. Marine polysaccharides in pharmaceutical applications: An overview. Marine Drugs 2010, 8, 24352465.

[147] Walter, J.; Sehrt, J.; Vrabec, J.; Hasse, H. Molecular dynamics and experimental study of conformation change of poly(N-isopropylacrylamide) hydrogels in mixtures of water and methanol. The Journal of Physical Chemistry B 2012, $116,5251-5259$.

[148] Aghbashlo, M.; Hosseinpour, S.; Mujumdar, A.S. Application of artificial neural networks (ANNs) in drying technology-A comprehensive review. Drying Technology 2015, 33, 1397-1462.

[149] Liu, H.; Chaudhary, D. The moisture migration behavior of plasticized starch biopolymer. Drying Technology 2011, $29,278-285$.

[150] Andreuccetti, C.; Carvalho, R.A.; Galicia-García, T.; Martínez-Bustos, F.; Grosso, C.R.F. Effect of surfactants on the functional properties of gelatin-based edible films. Journal of Food Engineering 2011, 103, 129-136.

[151] Gulrez, S.K..; Al-Assaf, S.; Phillips, G.O. Hydrogels: methods of preparation, characterisation and applications in molecular and environmental bioengineering. , in: Carpi, A. (Ed.), Progress in Molecular and Environmental Bioengineering - From Analysis and Modeling to Technology Applications 2011. pp. 117-150.

[152] ASTM. ASTM E96 / E96M-14: Standard Test Methods for Water Vapor Transmission of Materials 2014. West Conshohocken, PA.

[153] Kokoszka, S.; Debeaufort, F.; Lenart, A.; Voilley, A. Water vapour permeability, thermal and wetting properties of whey protein isolate based edible films. International Dairy Journal 2010, 20, 53-60. 
[154] Hagenmaier, R.D.; Shaw, P.E. Moisture permeability of edible films made with fatty acid and (hydroxypropyl)methylcellulose. Journal of Agricultural and Food Chemistry 1990, 38, 1799-1803.

[155] McHugh, T.H.; Avenabustillos, R.; Krochta, J.M. Hydrophilic edible films - modified procedure for water-vapor permeability and explanation of thickness effects. Journal of Food Science 1993, 58, 899-903.

[156] Olivas, G.I.; Barbosa-Canovas, G. Edible films and coatings for fruits and vegetables, in: Embuscado, M.E., Huber, K.C. (Eds.), Edible Films and Coatings for Food Applications 2009. Springer, pp. 211-244.

[157] Laurienzo, P.; Cammarota, G.; Di Stasio, M.; Gentile, G.; Laurino, C.; Volpe, M.G. Microstructure and olfactory quality of apples de-hydrated by innovative technologies. Journal of Food Engineering 2013, 116, 689-694.

[158] Higueras, L.; López-Carballo, G.; Gavara, R.; Hernández-Muñoz, P. Reversible covalent immobilization of cinnamaldehyde on chitosan films via Schiff base formation and their application in active food packaging. Food and Bioprocess Technology 2015, 8, 526-538.

[159] Fernández-Pan, I.; Ziani, K.; Pedroza-Islas, R.; Maté, J.I. Effect of drying conditions on the mechanical and barrier properties of films based on chitosan. Drying Technology 2010, 28, 1350-1358.

[160] Fang, X.; Vitrac, O. Predicting diffusion coefficients of chemicals in and through packaging materials. 2015, 33, 1104.

[161] Tiwari, S.; Bhattacharya, S. Dehumidifier-assisted drying characteristics of nutrient enriched gellan and agar gels. Drying Technology 2015, 33, 1491-1499.

[162] Petriccione, M.; Sanctis, F. De; Pasquariello, M.S.; Mastrobuoni, F.; Rega, P.; Scortichini, M.; Mencarelli, F. The effect of chitosan coating on the quality and nutraceutical traits of sweet cherry during postharvest life. Food and Bioprocess Technology 2015, 8, 394-408.

[163] Prakash, B.; Bingol, G.; Pan, Z. Moisture diffusivity in rice components during absorption and desorption. Drying Technology 2011, 29, 939-945. 
[164] Santos, P.H.S.; Silva, M.A. Retention of vitamin C in drying processes of fruits and vegetables-A review. Drying Technology 2008, 26, 1421-1437.

[165] Sarao, L.K.; M, A. Probiotics, prebiotics and microencapsulation - A review. Critical Reviews in Food Science and Nutrition 2015, 00-00.

[166] Chen, J.; Wang, Q.; Liu, C.; Gong, J. Issues deserve attention in encapsulating probiotics: critical review of existing literature. Critical Reviews in Food Science and Nutrition 2015, 00-00.

[167] Andersson, C.; Järnström, L.; Fogden, A.; Mira, I.; Voit, W.; Zywicki, S.; Bartkowiak, A. Preparation and incorporation of microcapsules in functional coatings for self-healing of packaging board. Packaging Technology and Science 2009, 22, 275-291.

[168] Mihindukulasuriya, S.D.F.; Lim, L.-T. Nanotechnology development in food packaging: A review. Trends in Food Science \& Technology 2014, 40, 149-167.

[169] McClements, J.; McClements, D.J. Standardization of nanoparticle characterization: methods for testing properties, stability and functionality of edible nanoparticles. Critical Reviews in Food Science and Nutrition 2015, 0000.

[170] Frank, X.; Perré, P. The potential of meshless methods to address physical and mechanical phenomena involved during drying at the pore level. Drying Technology 2010, 28, 932-943.

[171] Kulasinski, K.; Guyer, R.; Derome, D.; Carmeliet, J. Water adsorption in wood microfibril-hemicellulose system: Role of the crystalline-amorphous interface. Biomacromolecules 2015, 16, 2972-2978.

[172] Kulasinski, K.; Keten, S.; Churakov, S. V; Guyer, R.; Carmeliet, J.; Derome, D. Molecular mechanism of moistureinduced transition in amorphous cellulose. ASC Macro Letters 2014, 3, 1037-1040.

[173] Ho, Q.T.; Carmeliet, J.; Datta, A.K.; Defraeye, T.; Delele, M.A.; Herremans, E.; Opara; Ramon, H.; Tijskens, E.; van der Sman, R.G.M.; Van Liedekerke, P.; Verboven, P.; Nicolai, B. Multiscale modeling in food engineering. Journal of Food Engineering 2013, 114, 279-291. 
[174] Perré, P. Multiscale aspects of heat and mass transfer during drying. Transport in Porous Media 2007, 66, 59-76.

[175] Perré, P.; Rémond, R.; Aléon, D. Energy saving in industrial wood drying addressed by a multiscale computational model: board, stack, and kiln. Drying Technology 2007, 25, 75-84.

[176] Perré, P.; Rémond, R.; Colin, J.; Mougel, E.; Almeida, G. Energy consumption in the convective drying of timber analyzed by a multiscale computational model. Drying Technology 2012, 30, 1136-1146.

[177] Halder, A.; Datta, A.K.; Spanswick, R.M. Water transport in cellular tissues during thermal processing. AlChE Journal 2011, 57, 2574-2588.

[178] Khwaldia, K.; Perez, C.; Banon, S.; Desobry, S.; Hardy, J. Milk proteins for edible films and coatings. Critical Reviews in Food Science and Nutrition 2004, 44, 239-251.

[179] Derluyn, H.; Janssen, H.; Carmeliet, J. Influence of the nature of interfaces on the capillary transport in layered materials. Construction and Building Materials 2011, 25, 3685-3693. 


\section{ENVIRONMENT}

Radiation (absorption at surface and in Convection of
material (e.g. microwave) \& emission)

Air flow

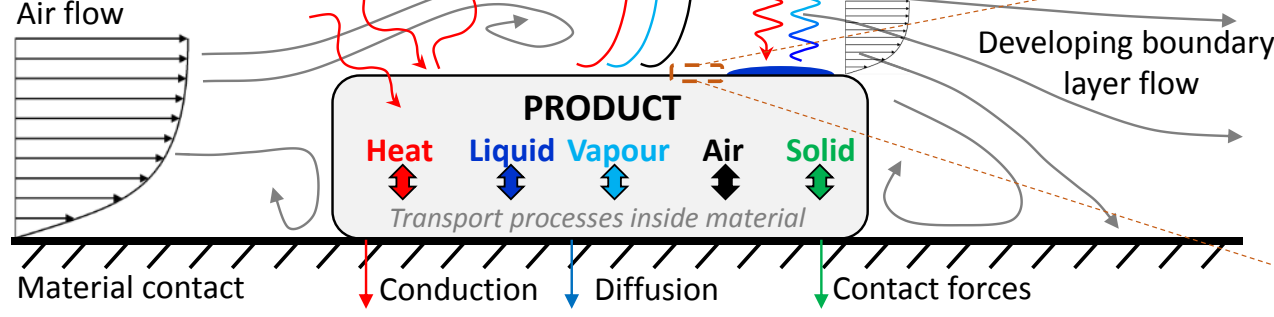

Close-up of air-material interface

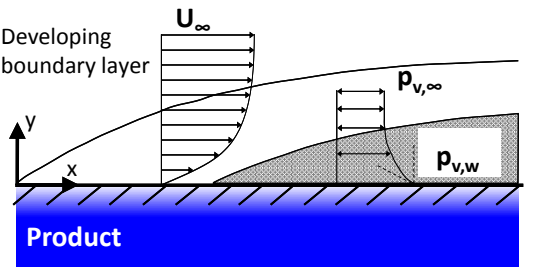

Figure 1. Transport processes inside porous material (product) and exchange processes at product-environment

interfaces (adapted from [10]), with a close-up of the air-material interface for a developing boundary layer (U = air speed, $p_{v}=$ vapour pressure, $\infty=$ free-stream value). The environment includes the surrounding air (depicted on the right) as well as contact with solid or porous materials, for example process equipment or other products. 
(a) Discretely-distributed microscopic moisture sources
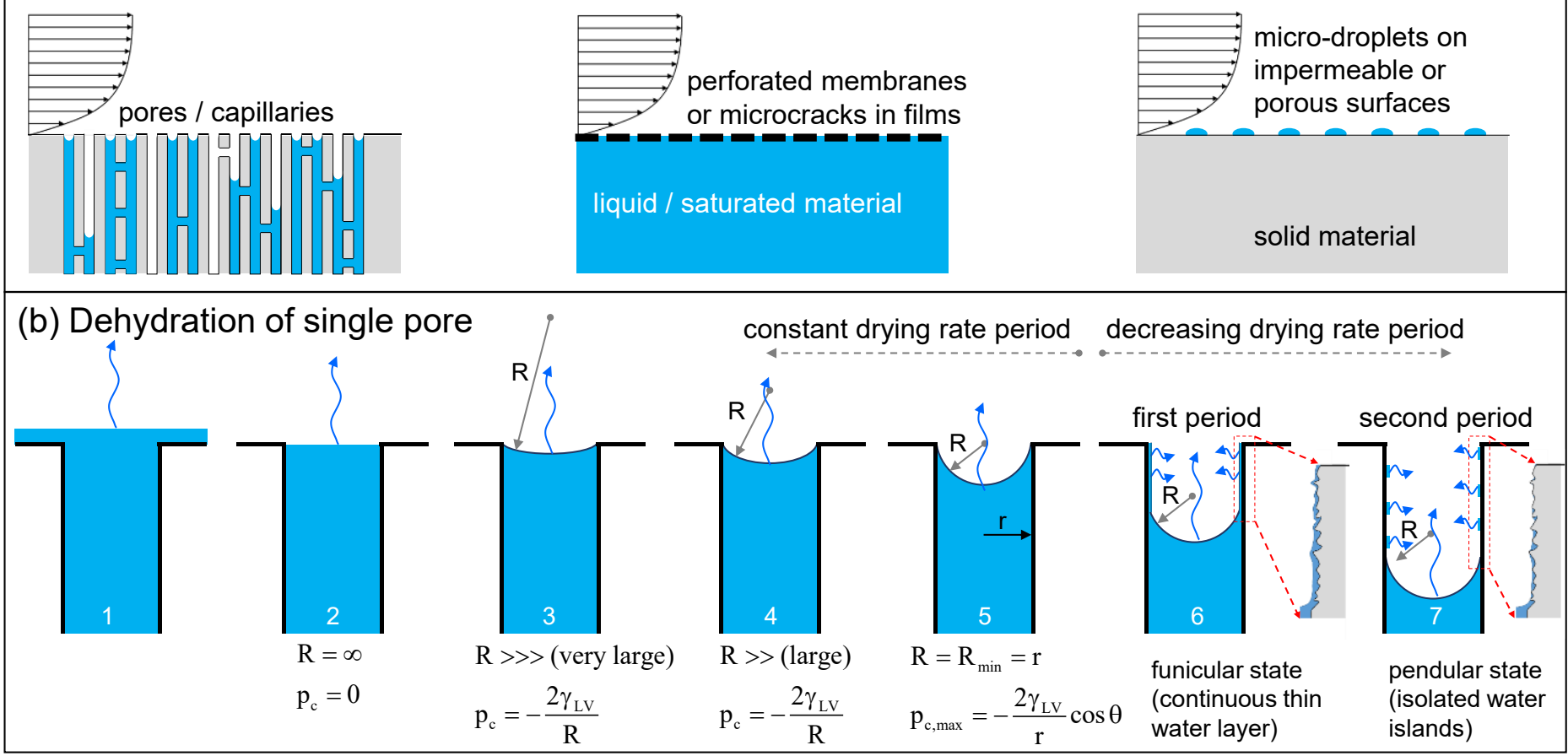

Figure 2. (a) Surfaces that are only partially covered with moisture sources at the product-environment interface; (b)

Dehydration stages of a single (non-deformable) pore ( $p_{c}$ : capillary pressure, $\gamma_{L v}$ : surface tension between liquid and vapour, R: radius of curvature of the meniscus, $r$ : pore radius, $\theta$ : contact angle). 


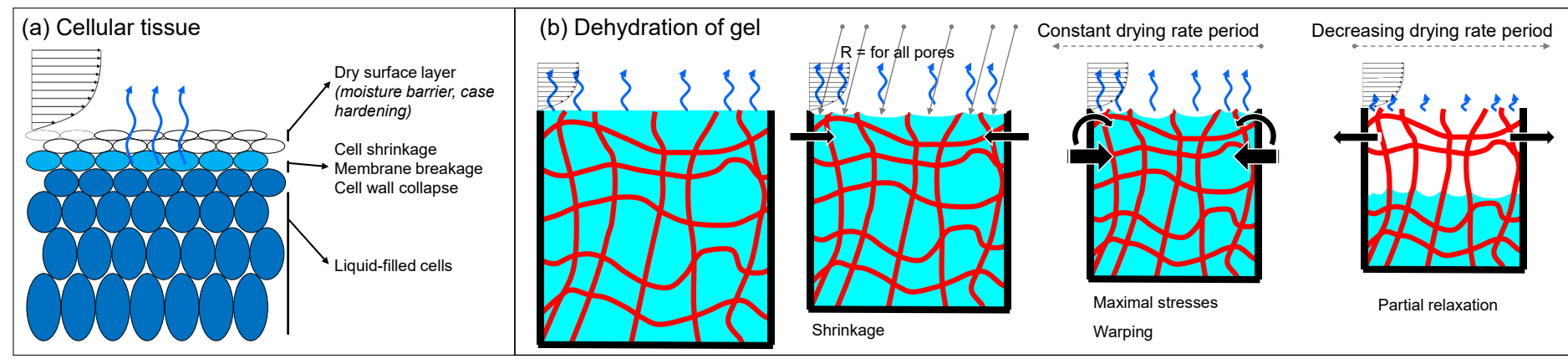

Figure 3. Dehydration of (a) cellular tissue, such as fruit, (b) a hydrogel (adapted from [27], $R$ : radius of curvature of the meniscus, which is equal for all pores exposed to the same capillary pressure). 


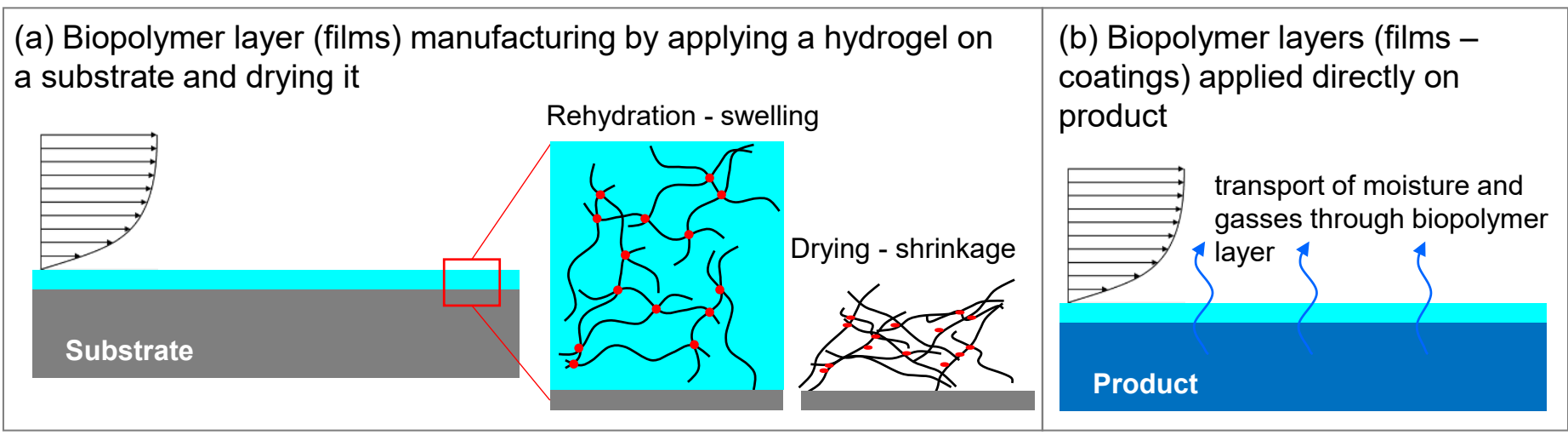

Figure 4. Dehydration of biopolymer layers (a) during a-priori manufacturing by applying it on a substrate and drying it and (b) applied (coated) directly onto the product. 


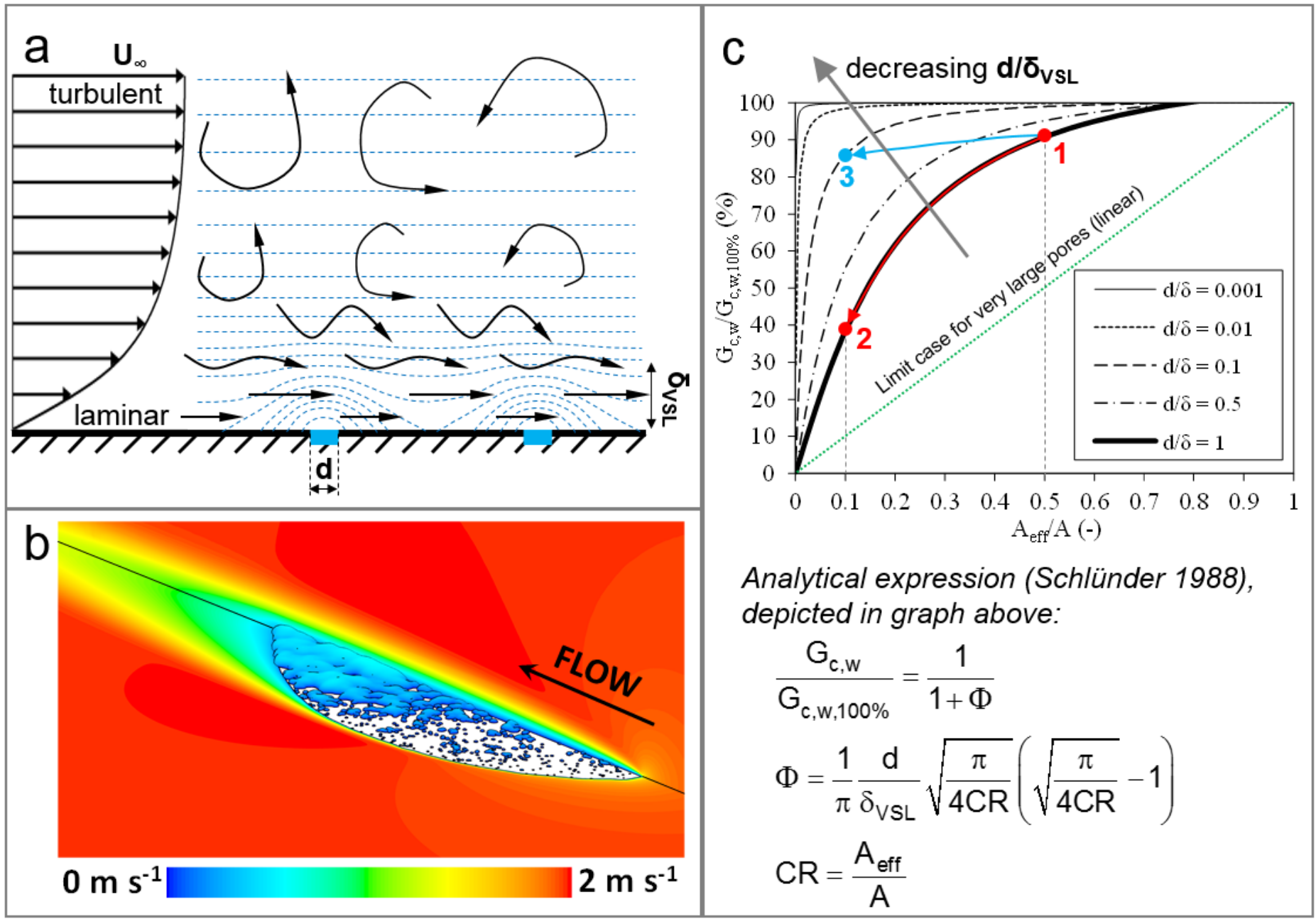

Figure 5. (a) Schematic of water vapour concentration contours, in blue dash lines, in the boundary layer over a surface with discretely-distributed moisture sources (indicated in blue) with indication of $d, \delta_{V S L}$ and laminar and turbulent regions in the boundary layer ( $d=$ size of the sources, $\delta_{v s L}=$ thickness of the viscous sublayer). (b) IIlustration of evaporation from discrete stomata from a leaf via the boundary layer (from [41]). A single water vapour concentration isocontour is shown, coloured according to air speed, where the air speeds in a horizontal and vertical centreplane are also shown. (c) Mass flow rate as a function of the surface coverage ratio $(C R=A$ eff/A) for different $d / \delta_{v s L}$ ratios (from [18]), based on the analytical equation of Schlünder [42], which is also given. The mass flow rate form a partially covered surface $\left(G_{c, w}\right)$ is scaled with that of a surface with a coverage ratio of $100 \%\left(G_{c, w, 100 \%}\right)$. Points 1, 2 and 3 indicate different stages in the drying process of droplets. 


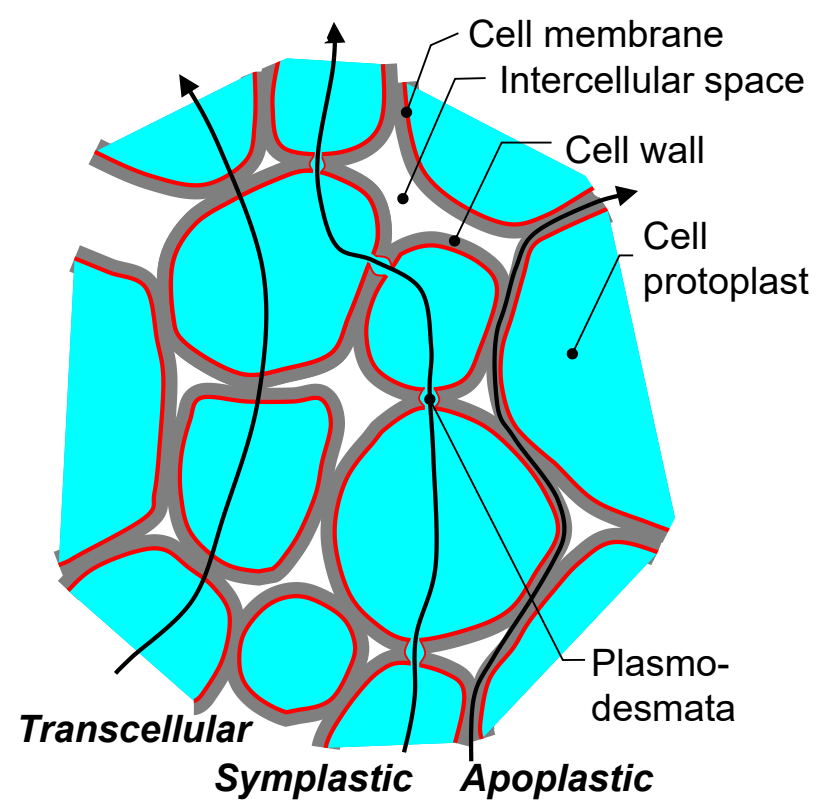

Transport pathways

Figure 6. Cellular water transport pathways (adjusted from [59]). 


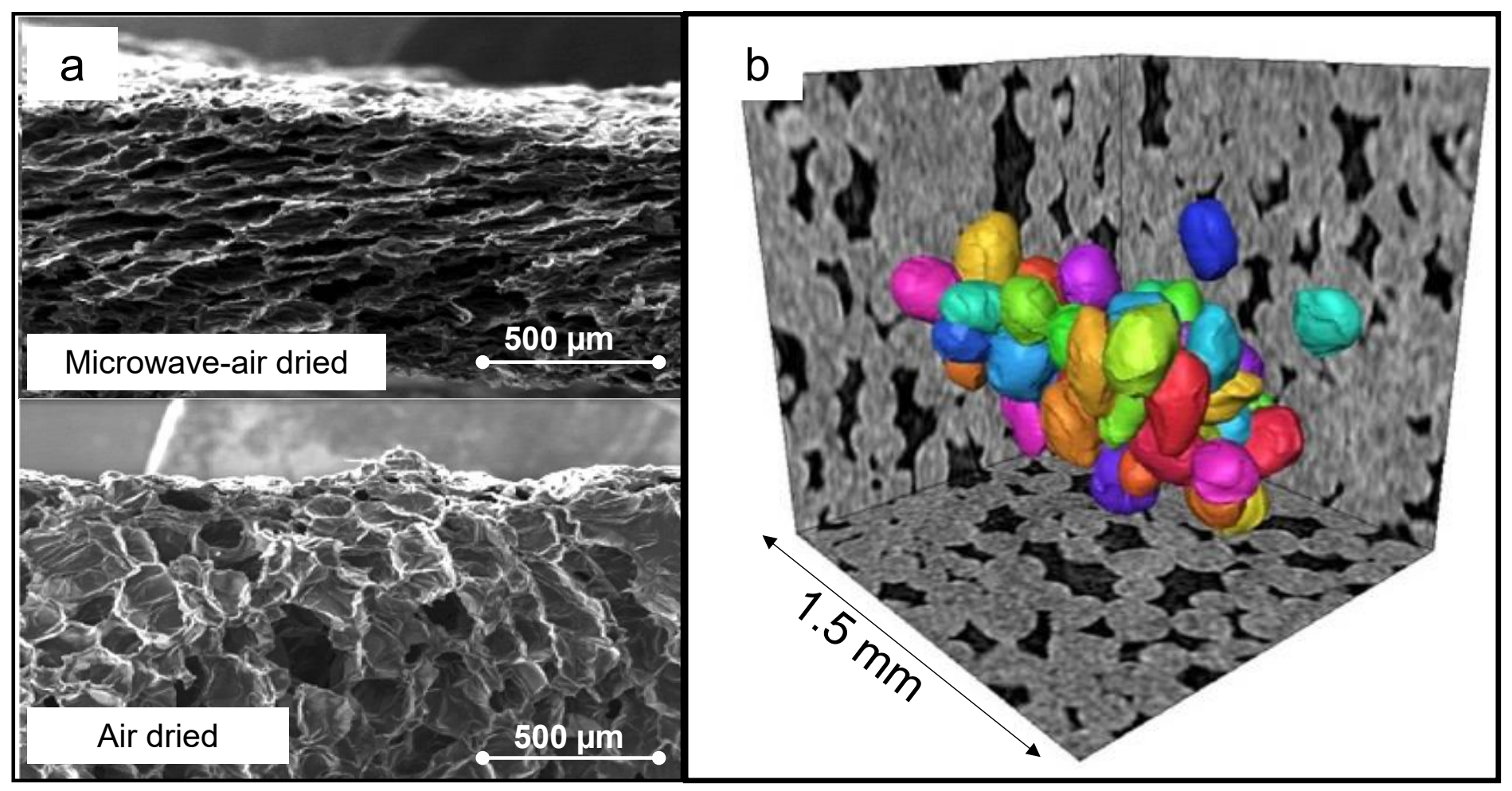

Figure 7. (a) Dried apples slice imaged from scanning electronic microscopy [60]. (b) Apple parenchyma cells of fresh tissue imaged with X-ray tomography and segmented for visualisation [61]. 


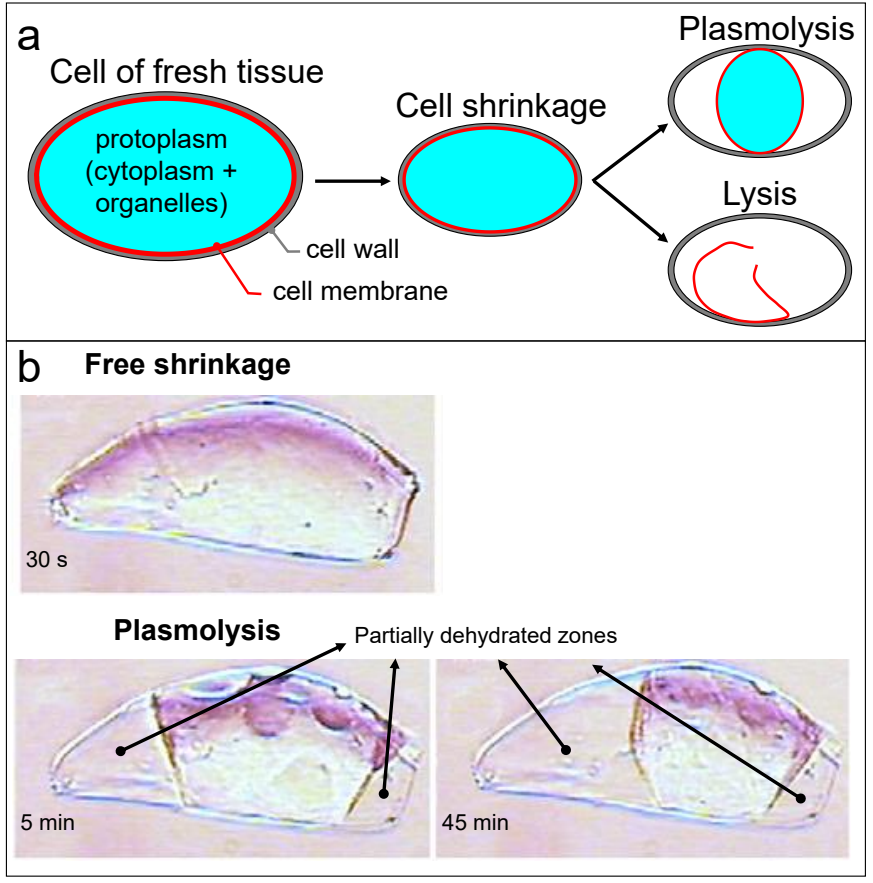

Figure 8. (a) Different stages of dehydration of a single cell. (b) Osmotic dehydration of an isolated apple cell (from [65]). 


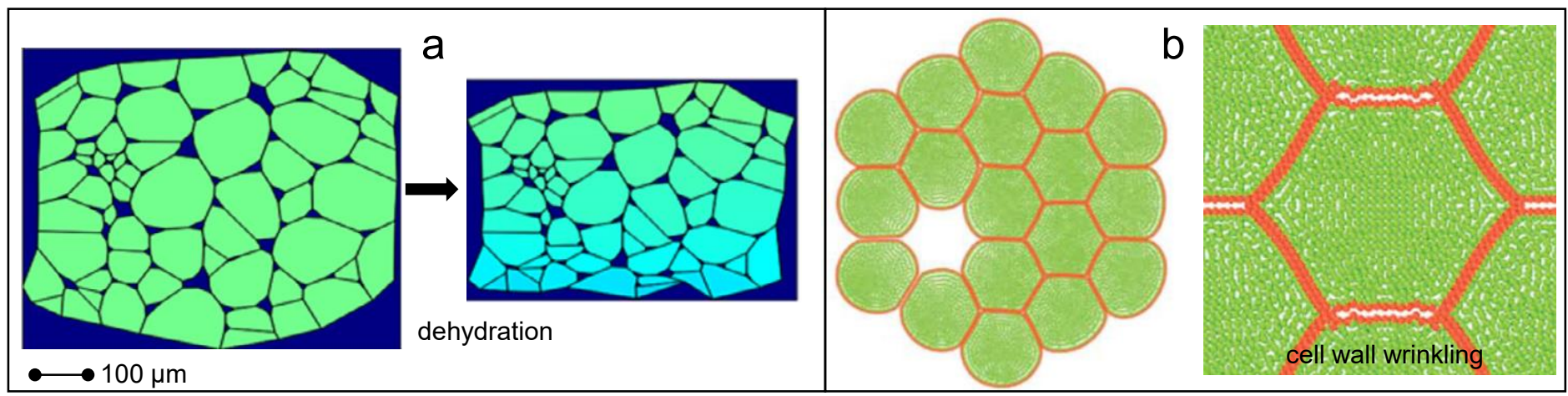

Figure 9. Examples of hygro-micromechanical models of cellular tissue. (a) Fresh and partially dehydrated tissue [58].

(b) Deformed cellular structure using SPH-DEM [78] (smoothed particle hydrodynamics-discrete element method, published by The Royal Society of Chemistry). 
1. SOL

biopolymers

2. GEL

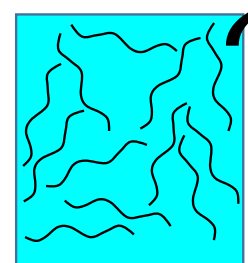

physical cross-links

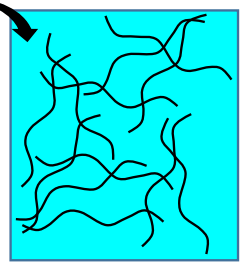

3. DRYING

xerogel cross-links
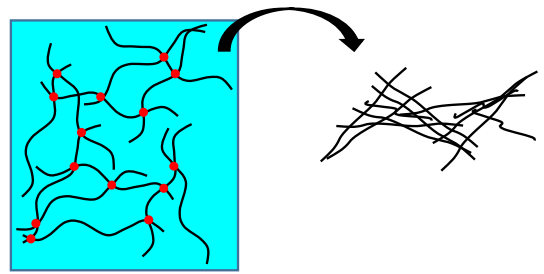

4. REHYDRATION

hydrogel

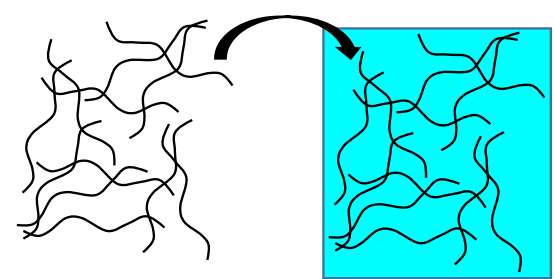

Figure 10. Typical sol-gel process for a hydrogel. 

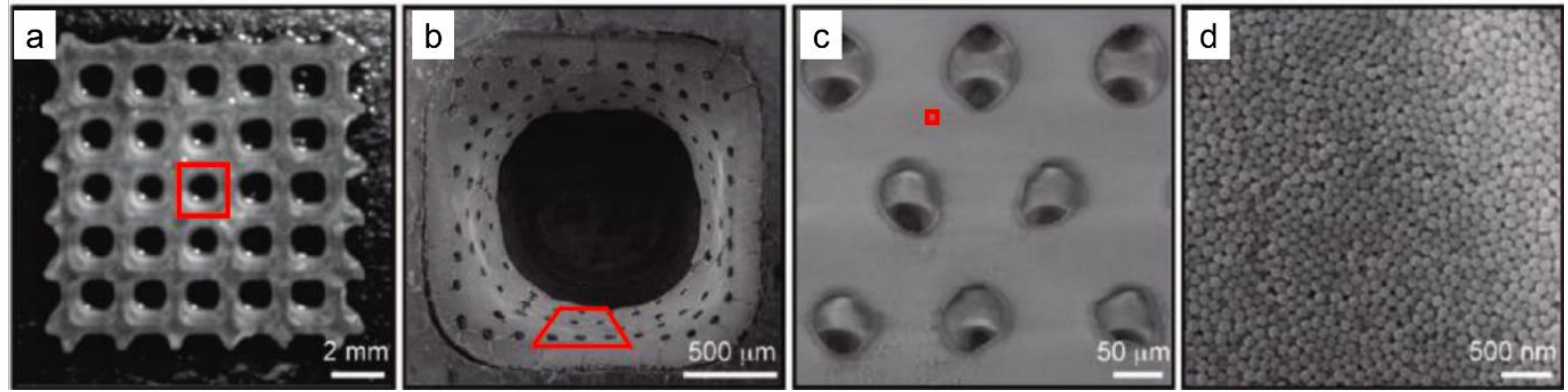

Figure 11. Field emission scanning electron microscopy (FESEM) images of a hierarchical porous structure (reprinted (adapted) with permission from [136]. Copyright (2011) American Chemical Society). In the sequence from left (a) to right (d), the red rectangles indicate the areas magnified in the right image. 


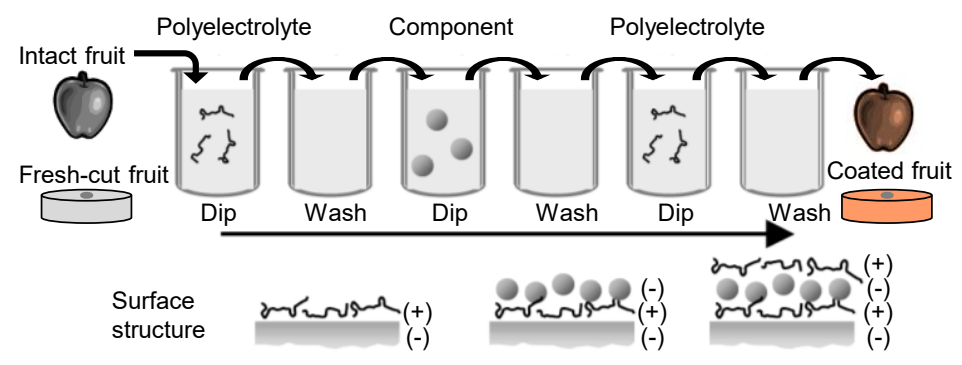

Figure 12. Illustration of multilayer coating of intact or minimally-processed fruit by layer-by-layer deposition (adapted from [118]). 


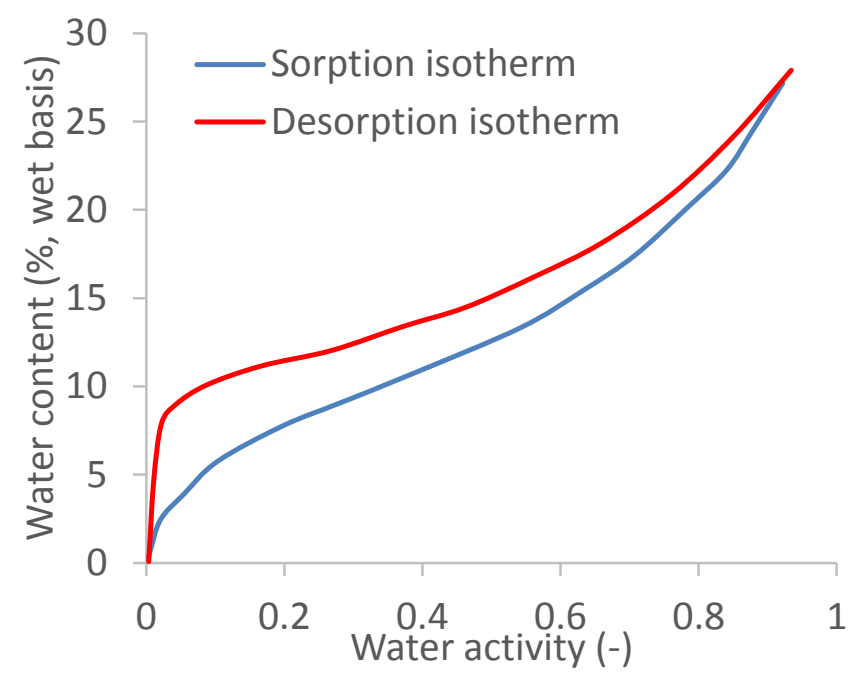

Figure 13. Sorption and desorption isotherm for a gelatine film (data from [122]). 

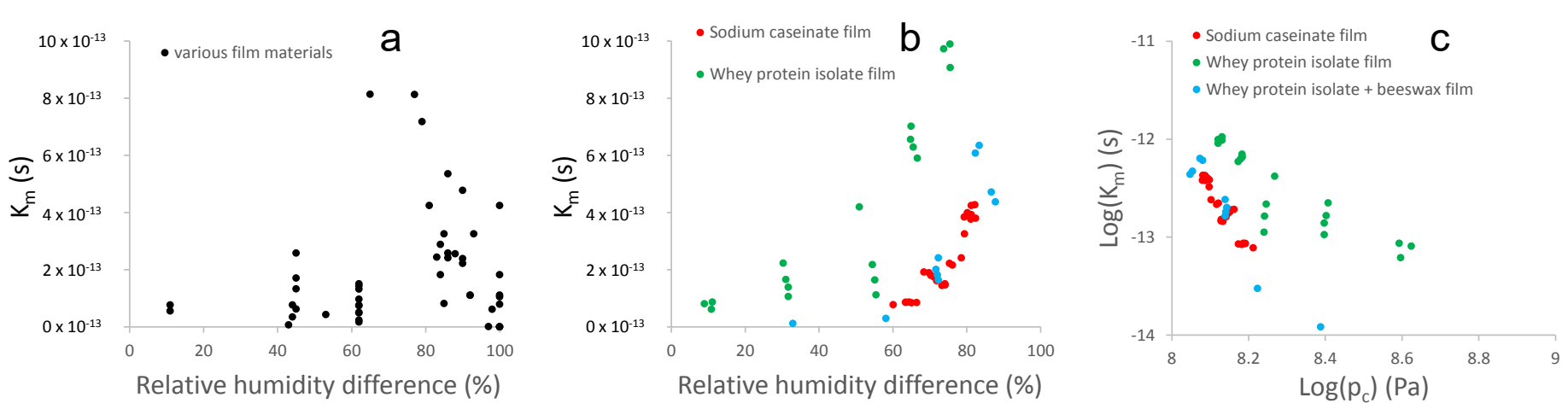

Figure 14. Moisture permeability (or water vapour permeability WVP): (a) for many different films (each point represents a specific case), as a function of the relative humidity difference that is imposed over the film (data from $[113,178]) ;(b, c)$ for three films (data from [155]) as a function of (b) several relative humidity differences that are imposed over each of the films, with the RH at one side of the film being $0 \%$ for all cases, (c) the corresponding average capillary pressure within the film (from (b), log-log scale), calculated from the average RH in the film. 


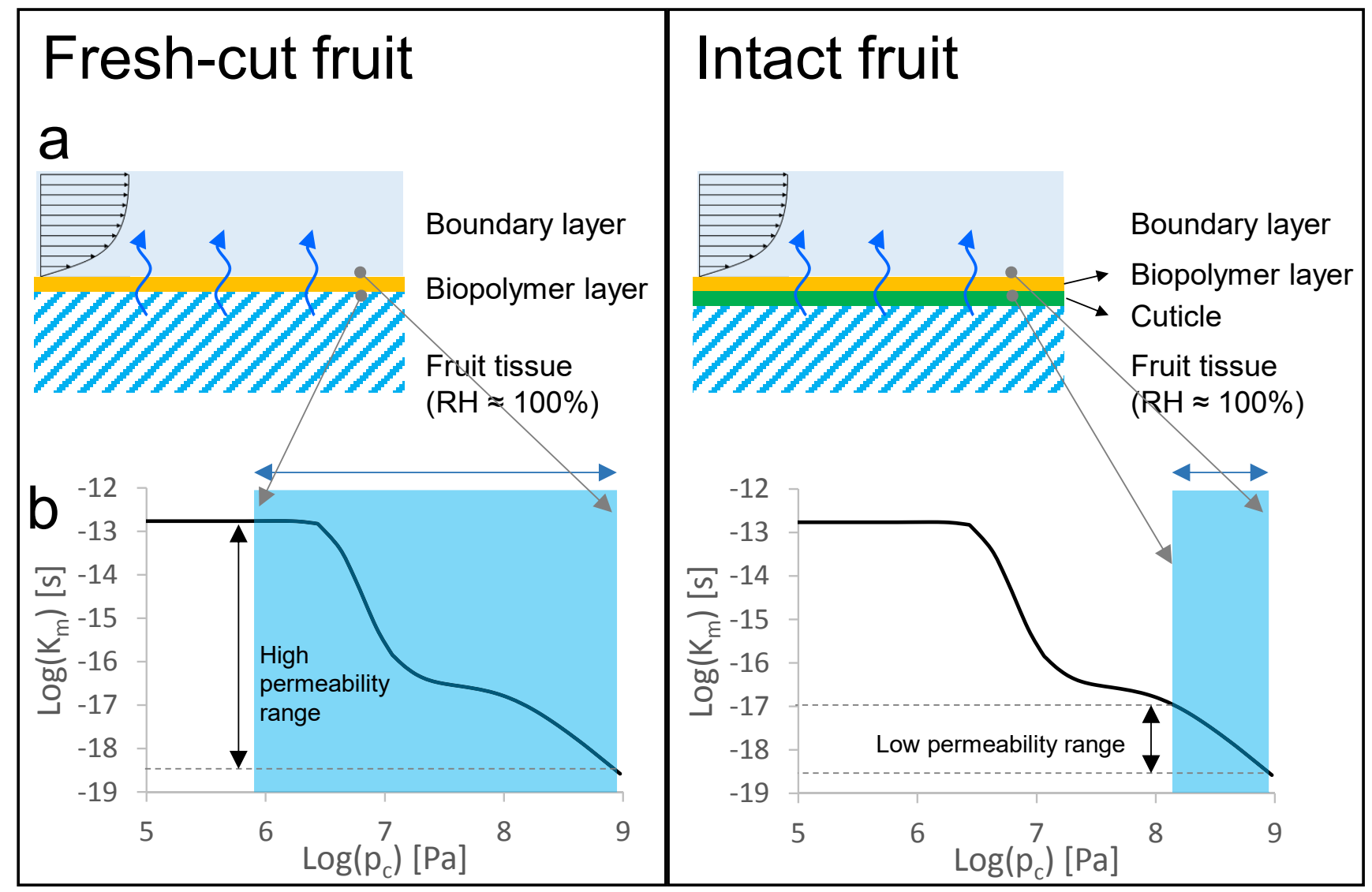

Figure 15. Illustration of possible impact of humidity of the product on the moisture permeability of permeable biopolymer layers, for the example of fresh-cut (left) and intact fruit (right): (a) schematic of cross section; (b) permeability as a function of capillary pressure (log-log scale) for a typical porous material [179], with illustration of the water activity range in the biopolymer layer in blue. 